Boletín de la Sociedad Geológica Mexicana

VOLUMEN 64, NÚM. 3, 2012, P. 319-333

\title{
Geoquímica de los sistemas de flujo de agua subterránea en rocas sedimentarias y rocas volcanogénicas de Loreto, BCS, México
}

\author{
Antalia González-Abraham ${ }^{1, *}$, Juan Reynerio Fagundo-Castillo², José Joel Carrillo-Rivera ${ }^{3}$, \\ Ricardo Rodríguez-Estrella ${ }^{1}$ \\ ${ }^{1}$ Centro de Investigaciones Biológicas del Noroeste S.C., Mar Bermejo No. 195, Col. Playa Palo de Santa Rita Apdo. Postal 128, CP \\ 23090, La Paz, B. C. S., México. \\ ${ }^{2}$ Centro Nacional de Medicina Natural y Tradicional, Calle 28 No. 4115, Municipio Playa, La Habana, Cuba. \\ ${ }^{3}$ Instituto de Geografía, Universidad Nacional Autónoma de México Ciudad Universitaria, Coyoacán, 04510, México D. F. \\ *agonzalez@cibnor.mx
}

\section{Resumen}

La composición química del agua subterránea es el resultado de continuos procesos de interacción entre el agua de precipitación (y nieve o granizo), que se infiltra en el terreno, y los minerales de la litología por donde circula. El objetivo del presente estudio es determinar el origen de la composición química del agua subterránea del área de Loreto, Baja California Sur. Para ello se utilizaron modelos hidrogeoquímicos de balance de masa y mezcla de aguas, así como otras herramientas de la hidrogeoquímica. Los procesos relacionados se manifiestan en un aumento en la concentración $\mathrm{Cl}^{-}, \mathrm{Br}, \mathrm{I}^{-}, \mathrm{As}_{\text {total }}$, B- Li y Sr. Se identificaron 7 grupos de agua que corresponden a manantiales someros, pozos, manantiales termales y manantiales submarinos. Los patrones hidrogeoquímicos principales obtenidos se relacionan con flujos específicos de agua subterránea que son típicos de procesos de disolución de plagioclasa del tipo albita, andesina y oligoclasa. Los patrones restantes resultado de la mezcla de agua de diferentes flujos, muestran influencia de procesos de intercambio iónico. De esta manera, la composición química del agua que circula en esta área a través de rocas volcánicas félsicas y sus sedimentos derivados debe su origen a la meteorización de los mismos. La mezcla de agua y los procesos de interacción agua-roca se dan entre flujos de tipo local y otros de jerarquía intermedia o regional. Además, la influencia del clima árido y el intensivo desarrollo agrícola, juegan también un papel importante en el modo en que el agua subterránea adquiere su composición química en el área.

Palabras clave: Patrones hidrogeoquímicos, química de fluidos, zonas áridas, Loreto.

\begin{abstract}
The chemical composition of groundwater is the result of continuous water-rock interaction between rain water (and hail or snow) that filters into the ground and the minerals in the lithology it flows through. The objective of this study is to determine the origin of the chemical composition of groundwater in the Loreto area, Baja California Sur. Hydrogeochemical mass balance and water mixture models as well as other hydrogeochemical tools were used. All related processes are marked by an increase in the concentrations of $\mathrm{Cl}, \mathrm{Br}, \mathrm{I}, \mathrm{As} \mathrm{total}_{\mathrm{l}} \mathrm{B}, \mathrm{Li}$ and $\mathrm{Sr}$. We identified seven groups of water corresponding to shallow springs, wells, thermal springs and submarine springs. The hydrogeochemical patterns of the underground water flows (defined numerically and by graphic expressions of water chemistry) are related to the prevailing lithology and are typical of albite, andesine and oligoclase dissolution. The remaining patterns result from the mixture of different groundwater flows, and show influence of ionic exchange processes. Thus, the chemical composition of groundwater circulating through the felsic volcanic rocks and their derived sediments has its origin in the weathering of those materials. Processes of water-rock interaction and water mixture take place among local flows and others of intermediate or regional hierarchy. Furthermore, the influences of the arid climate and intensive agriculture development also play an important role in how groundwater in the area acquires its chemical composition.
\end{abstract}


Keywords: Hydrogeochemical patterns, fluid chemistry, arid zones, Loreto.

\section{Introducción}

La composición química del agua subterránea es el resultado de continuos procesos de interacción entre el agua de precipitación (y nieve o granizo) que se infiltra en el terreno y la litología por donde circula. Parte de los componentes químicos son adquiridos en la zona de recarga, mientras que otros se adquieren en el largo recorrido del flujo del agua subterránea hasta que ésta es captada en pozos o emerge en la zona de descarga a través de un manantial. En ese recorrido se puede originar un flujo de diferente naturaleza, de carácter local, intermedio o regional (Tóth, 2000), lo cual depende de la trayectoria de recorrido del agua subterránea en términos de su longitud y profundidad de recorrido y el tiempo de residencia del agua en el subsuelo. El anión predominante evoluciona, por lo general, desde facies hidrogeoquímicas de tipo $\mathrm{HCO}_{3}^{-}$, distintiva en flujos de corto recorrido (local), pasando por facies de tipo $\mathrm{SO}_{4}^{2-}$ , típica en flujos de mayor recorrido (intermedio), hasta facies $\mathrm{Cl}^{-}$, característica en la descarga de flujos de muy largo recorrido (los regionales) (Tóth, 2000). El tipo de catión depende de la litología (en el sentido estricto, de la mineralogía) atravesada por el agua: $\mathrm{Ca}^{2+}$, en carbonatos donde predominan la calcita o plagioclasas cálcicas, ricas en anortita; $\mathrm{Ca}^{2+}>\mathrm{Mg}^{2+}$, en carbonatos de tipo dolomita y en rocas sedimentarias e ígneas, que contienen minerales con abundante $\mathrm{Ca}^{2+} \mathrm{y} \mathrm{Mg}^{2+}, \mathrm{Mg}^{2+}>\mathrm{Ca}^{2+}$, fundamentalmente en alumino-silicatos de tipo básico o ultrabásico. De esta manera, la presente investigación se realizó con base en la colecta de muestras de agua del área de estudio que incorpora dos tipos principales de evidencia de agua subterránea, pozos y manantiales perennes.

El estudio del origen de la composición química del agua, producto de diferentes procesos, ha sido abordado desde distintas perspectivas. Por ejemplo, el origen de la composición del agua de manantiales efímeros y perennes, resultado de procesos de meteorización, ha sido explicado aplicando modelos de balance de masa, por ejemplo en Sierra Nevada, E.U.A., (Garrels y Mackenzie, 1967). En este caso se reconstruyeron los principales minerales originales constitutivos de las rocas ígneas encontradas en campo (plagioclasa, andesina, biotita, $\mathrm{K}$-feldespato, montmorillonita). Estos autores hicieron extensiva esta aproximación para explicar el origen de la composición del agua subterránea que circula en otras rocas ígneas, identificando procesos de intemperismo en que la plagioclasa albita originaba $\mathrm{Na}^{+}$y $\mathrm{H}_{4} \mathrm{SiO}_{4}$ por disolución incongruente de caolinita y esmectita (Na-beideita). Por otro lado, el origen de la composición del agua de algunos lagos de Sierra Nevada fue analizada mediante un modelo de evaporación, donde fueron identificados procesos de precipitación de yeso, calcita, hidroxisilicatos de $\mathrm{Mg}^{2+} \mathrm{y}$ $\mathrm{SiO}_{2}$ amorfo (Garrels y Mackenzie, 1967).

El origen de la composición química del agua puede determinarse mediante modelos hidrogeoquímicos inversos (que es una aproximación de balance de masa), y por medio de modelos de mezcla (i.e., de aguas de diferente calidad). Los primeros se basan en la transferencia de masa a partir de datos químicos, isotópicos y mineralógicos observados. Los mismos fueron desarrollados como una estrategia determinista para interpretar la composición química del agua subterránea, a partir de identificar cuantitativamente las reacciones geoquímicas que dan origen a esa composición. Entre estos modelos se pueden citar BALANCE (Parkhurst et al., 1982) y MODELAGUA(Fagundo-Sierra et al., 2001).

En forma similar, el origen de la composición química del agua que circula por rocas sedimentarias y volcánicas (caliza, caliza dolomitizada, calcarenita, arenisca y serpentinita) se ha determinado utilizando modelos de balance de masa y mezcla de aguas (Fagundo-Sierra et al., 2001) así como modelos hidrogeoquímicos basados en equilibrio químico en la Sierra del Rosario, Cuba (Fagundo et al., 2006; ver recopilación en Fagundo et al., 2008). Los principales procesos de intemperismo, en este caso, se producen por disolución congruente de calcita, dolomita y serpentinita, y por disolución incongruente de la plagioclasa albita y microclina. En el agua que circula en medio cárstico costero, contiguo a un humedal de la Cuenca Sur de La Habana, se identificaron, principalmente, procesos de disolución y precipitación de calcita, reducción anaeróbica de sulfato e intercambio iónico directo e inverso entre $\mathrm{Na}^{+}$ y $\mathrm{Ca}^{2+}$ así como dolomitización (Fagundo et al., 2004). En estos trabajos se han utilizado, además, las ventajas que ofrece la teoría de los patrones hidrogeoquímicos (Fagundo, 1998) con el fin de interpretar la relación entre la composición química del agua y el medio geológico por el que ésta ha circulado.

En el Valle de Santo Domingo, Baja California Sur, México, se han identificado varios procesos hidrogeológicos vinculados con la composición química del agua subterránea. Cardona et al. (2004) reportan procesos diagenéticos debido a la interacción de material geológico de origen marino con agua subterránea de baja salinidad, identificando el efecto de efluentes originados por la intensa actividad agrícola (retorno de riego), los cuales se infiltran hacia la zona saturada modificando la química del sistema de flujo natural. Asimismo, se identificó que debido a la extracción de agua por bombeo se induce, en algunos sitios, cierto flujo lateral de agua marina procedente de la línea costera. Sin embargo, el principal efecto de incremento de salinidad en el agua 
extraída no es el clásico efecto de avance de agua de mar. El agua salada existente en los sedimentos subyacentes llega ascendiendo a los pozos de extracción en forma vertical, esto se debe a su rapidez de ascenso en varios órdenes de magnitud mayor al avance lateral del agua de mar (Cardona et al., 2004). Los resultados indican que la composición química del agua subterránea está controlada por la geoquímica de los carbonatos y reacciones de intercambio iónico (tanto directo como inverso). Esto parece congruente con lo encontrado en Bahía Concepción, B. C. S., donde la concentración de $\mathrm{F}, \mathrm{Li}$, Ba y $\mathrm{Sr}$ sugiere que el extremo salino de la mezcla de agua difiere de la composición química del agua marina (Prol-Ledesma et al., 2007). En esta área, también se ha estudiado la composición química de agua que sugiere la presencia de flujos intermedio y regional (de gran distancia y profundidad de recorrido) caracterizados por manantiales hidrotermales presentes cerca de la costa así como varios de tipo submarino que descargan en el fondo de Bahía Concepción (Canet et al., 2005; Prol-Ledesma et al., 2007).

El objetivo del presente trabajo es establecer el origen de la composición química del agua, utilizando esencialmente modelos que no han sido aplicados en el área de estudio, como los hidrogeoquímicos de balance de masa, mezcla de aguas y reconocimiento de patrones hidrogeoquímicos, así como otras herramientas hidrogeoquímicas que facilitan el entendimiento de la vinculación entre los sistema de flujo de agua subterránea, la litología por donde circula y el efecto de la actividad humana en la composición química del agua.

\section{2. Área de estudio}

El área de estudio está delimitada por límites políticoadministrativos y corresponde al municipio de Loreto; sin embargo, para poder entender el contexto hidrogeológico del área se utilizaron muestras de agua subterránea de sitios fuera del municipio.

El Municipio de Loreto se localiza en el estado de Baja California Sur, México y abarca una superficie de $4402 \mathrm{~km}^{2}$, (entre $26^{\circ} 33^{\prime} 11^{\prime \prime}$ y $25^{\circ} 12^{\prime} 15^{\prime \prime}$ latitud norte; $111^{\circ} 46^{\prime} 22^{\prime \prime}$ y $110^{\circ} 55^{\prime} 15^{\prime \prime}$ longitud oeste). Al N colinda con el Municipio de Mulegé, al S y E con el Municipio de Comondú; al E con el Golfo de California (Figura 1). Cuenta con una población de 11839 habitantes (INEGI, 2005). Las actividades principales son el turismo y la pesca. El principal uso de suelo en el municipio corresponde a la agricultura, ganadería, minería, pesca y turismo, principalmente.

Según la clasificación de García (1988) presenta clima árido, cálido con régimen de lluvias en verano BW(h') $\mathrm{HW}\left(\mathrm{x}^{\prime}\right)\left(\mathrm{e}^{\prime}\right)$. Las lluvias que se producen en verano son esporádicas de baja intensidad y corta duración, debido a que son resultado de ciclones debilitados. El régimen pluvial se caracteriza por presentar un periodo de escasa lluvia entre los meses de febrero a junio y un periodo de lluvias de agosto a septiembre con una media anual de $\approx 115 \mathrm{~mm}$

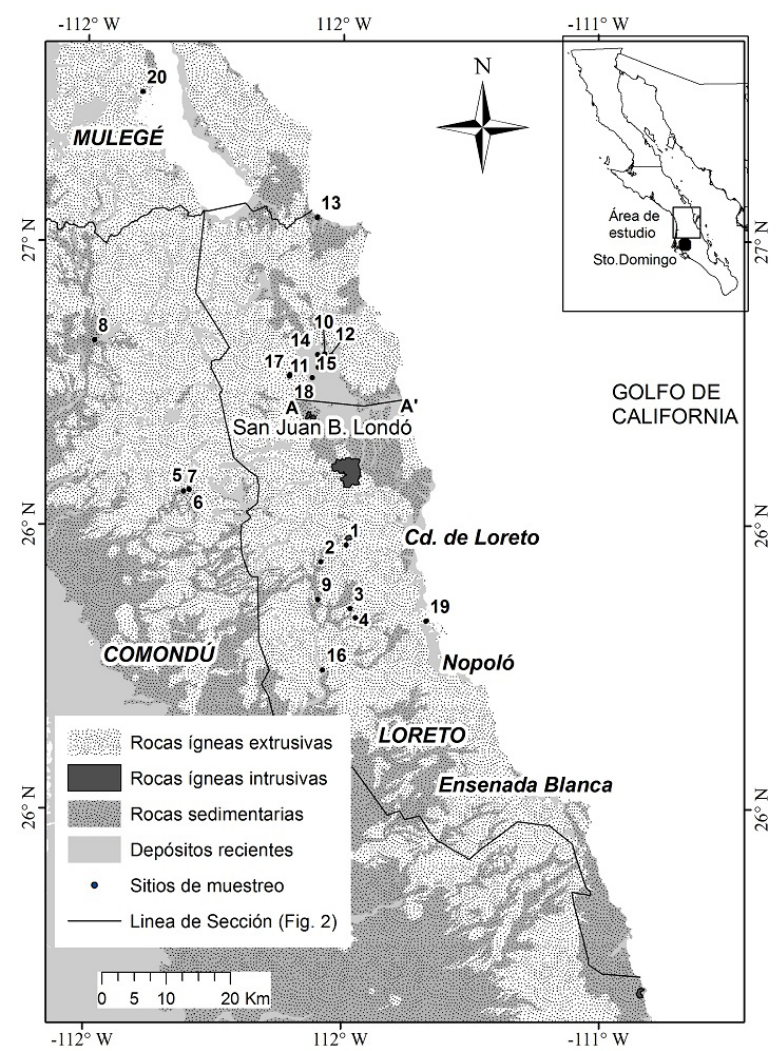

Figura 1. Localización del área de estudio, Loreto, B. C. S. La línea de sección se muestra en la figura 2. Adaptada de Carrillo-Rivera, 2000.

(Steinitz et al., 2005). La temperatura media anual es de $21^{\circ} \mathrm{C}$ (mínima $9^{\circ} \mathrm{C}$ y máxima $37.5^{\circ} \mathrm{C}$ ) (CONANP, 2000).

\subsection{Referente geológico}

El territorio correspondiente al área de Loreto se encuentra ubicado dentro de la provincia geológica denominada Faja Volcánica de la Sierra La Giganta. Su origen se remite al Mioceno temprano cuando la península se encontraba unida al macizo continental y el terreno era invadido por secuencias estrato-volcánicas y coladas de lava proveniente de volcanes en lo que hoy es la costa del estado de Sinaloa. Las rocas volcánicas que constituyen la Sierra de La Giganta fueron denominadas por Heim (1922) como Formación Comondú ( $T c o$ ), compuestas por material volcánico extrusivo así como sedimentario con un espesor superior a los $1000 \mathrm{~m}$. Posteriormente, Beal (1948) y MinaUhink (1957) limitaron esta definición a una secuencia de rocas volcánicas y vulcano-clásticas en la Sierra de la Giganta, donde el último autor estimó un espesor de $1200 \mathrm{~m}$. El Instituto de Geofísica (1986) sugiere, para esta formación, un espesor de $>3000 \mathrm{~m}$. Las partes topográficamente bajas y la planicie costera están representadas por grava y arena así como por un conglomerado de reciente formación que puede alcanzar en Loreto hasta los $70 \mathrm{~m}$ de espesor (Demant, 1975). Afloramientos presentes en el área permiten 
identificar cuatro unidades básicas: rocas ígneas extrusivas, rocas sedimentarias, depósitos recientes y rocas ígneas intrusivas.

Las rocas ígneas extrusivas están formadas por una secuencia estrato-volcánica y coladas de lava andesítica, toba dacitica, basalto, brecha volcánica, toba ácida y material vulcano-clástico y escasos derrames andesítico y dacítico. Estas rocas muestran fracturas y fallas normales escalonadas formando escarpes y terrazas estructurales; la variabilidad de estructura y composición química en sus afloramientos propicia intemperismo y erosión diferencial. Esta unidad representa el $66 \%$ del total de la superficie del área con una geomorfología de montañas y lomeríos con laderas escarpadas y mesetas aisladas con elevaciones de hasta $1680 \mathrm{msnm}$. Las condiciones físicas de estas rocas las hace de singular importancia en una comparativa rápida filtración y movimiento del agua subterránea que en turno le permiten tener una firma geoquímica particular (CarrilloRivera, 2000). Por su parte, las rocas sedimentarias, tienen intercalaciones de sedimentos marino y terrígeno en un ambiente de transgresión durante el Mioceno tardío hasta el Plioceno (Formación Salada, Tps), y se asocia a la apertura del Golfo de California; consiste en un espesor de más de $1200 \mathrm{~m}$ compuesto de arenisca, conglomerado y arenisca terrígena, limonita-arenisca y lutita-arenisca de origen marino, con alternancia de limolita y horizontes de coquina y conglomerado polimíctico. Cubriendo a estos materiales se encuentran andesita, basalto y brecha basáltica en un espesor conjunto que varía entre los 100 y $200 \mathrm{~m}$. Las rocas sedimentarias cubren $24.5 \%$ del área, con una geomorfología de pie de monte y escasamente de montaña y lomerío abrupto (Cardona et al., 2004).

Los depósitos recientes son de origen fluvial localizados en lechos de cauce de río (intermitente) resultado de la erosión de unidades adyacentes, se diferencian en terrazas y pie de monte $(Q p)$, y aluviones ( $Q a l)$ por su posición morfológica. En la parte $\mathrm{N}$ del área se encuentra arena media a fina de color gris con pocos clastos redondeados de origen volcánico mientras que al S se compone por arena media a gruesa de color claro. Se encuentra hacia el NO y extremo O del área ocupando el 9\% de su superficie.

Las rocas ígneas intrusivas, corresponden a un granito y granodiorita $(K g r)$ de edad Mesozoica que aflora en la parte media del área con una superficie que incorpora el $0.5 \%$ de la misma. El Kgr se manifiesta como bloques de color rosa y la granodiorita es gris oscuro; éste se presenta como lomeríos de pendiente suave y elevación de $<300 \mathrm{~m}$ (Bigioggero et al., 1996).

La geomorfología del área de Loreto corresponde a una angosta planicie costera de entre 1 y $4 \mathrm{~km}$ de ancho, la cual se extiende desde el poblado de Loreto hasta el sitio conocido como Ensenada Blanca. En este mismo referente, se encuentra San Juan B. Londó, hacia el límite N del área, el cual corresponde a una planicie aluvial con ligera pendiente al SE, que se eleva 30-40 m sobre la planicie.

Dorsey et al. (1997), estudiaron el proceso estratigráfico, sedimentológico y tectónico de la cuenca PliocenoCuaternaria del SE de Loreto encontrando litofacies que incluyen caliza siliclástica marina y caliza bioclásticas, contenidas por la Formación Comondú.

Por otro lado, Bigioggero et al. (1996) expusieron características estratigráficas y petrográficas del cinturón andesítico del Mioceno en el área de estudio que incluye, entre otras, una serie de domos dacítico-andesítico, algunos de ellos ricos en minerales como el piroxeno, anfíbol, biotita, plagioclasas, y raramente cuarzo.

Desde el punto de vista de estructura geológica la disposición de los materiales litológicos en el área de estudio pueden ejemplificarse como una estructura de pilares y fosas como la descrita para San Juan B. Londó (Carrillo-Rivera, 2000), donde la estructura está dominada y delimitada por un sistema de fallas N-NO de unos 100 $\mathrm{km}$ de longitud que cruzan varias cuencas superficiales. La roca basamento es el granito-granodiorita cuya topografía está cubierta por rocas de la Formación Comundú y material Cuaternario. El espesor conjunto de material volcánico Terciario y Cuaternario es de 1600 a > 3000 m (Instituto de Geofísica, 1986). Las fosas contienen piroclástos y flujos de lava inter-estratificados con sedimentos no consolidados (arcilla, limo, arenisca, y conglomerado). Es importante enfatizar que a lo largo de la Península los materiales volcánicos de la Formación Comondú están distribuidos más allá de cada cuenca superficial. En el área de estudio se encuentra presente una capa de material de grano fino y compacto (localmente referida como arcilla), de unos 50$100 \mathrm{~m}$ de espesor a unos $50 \mathrm{~m}$ por debajo de la superficie de la planicie; esta capa está cubierta por material aluvial del Cuaternario (Figura 3). La actividad geotérmica más cercana se presenta en Las Tres Vírgenes, unos $250 \mathrm{~km}$ al N de San Juan B Londó; es de anotar que la CFE (1998) reporta que la actividad tectónica ha producido un sistema de fallas y fracturas con una orientación N-NE el cual se vincula como una zona de conductividad hidráulica mayor que ha permitido la migración de flujos hidrotermales a la superficie.

\subsection{Referente hidrogeológico}

Varias de las unidades geológicas arriba descritas forman en el área un sistema acuífero constituido por dos acuíferos (Figura 2): uno menor, libre y colgado que se encuentra sobre otro aquí denominado Acuífero Principal, descritos por Carrillo-Rivera (2000) para San Juan B. Londó. El acuífero colgado es somero en material granular sedimentario y piro-clastos indiferenciados del Cuaternario y Mioceno, su espesor es de $50 \mathrm{~m}$ y sobre-yace a un cuerpo de arcilla compacta de 20 a $80 \mathrm{~m}$ de espesor que se considera cubre parcialmente la planicie en espesores diversos $(>100$ $\mathrm{m})$.

El Acuífero Principal es el que comúnmente se usa para extraer agua en la región; se encuentra en rocas fracturadas vulcano-sedimentarias y material granular 

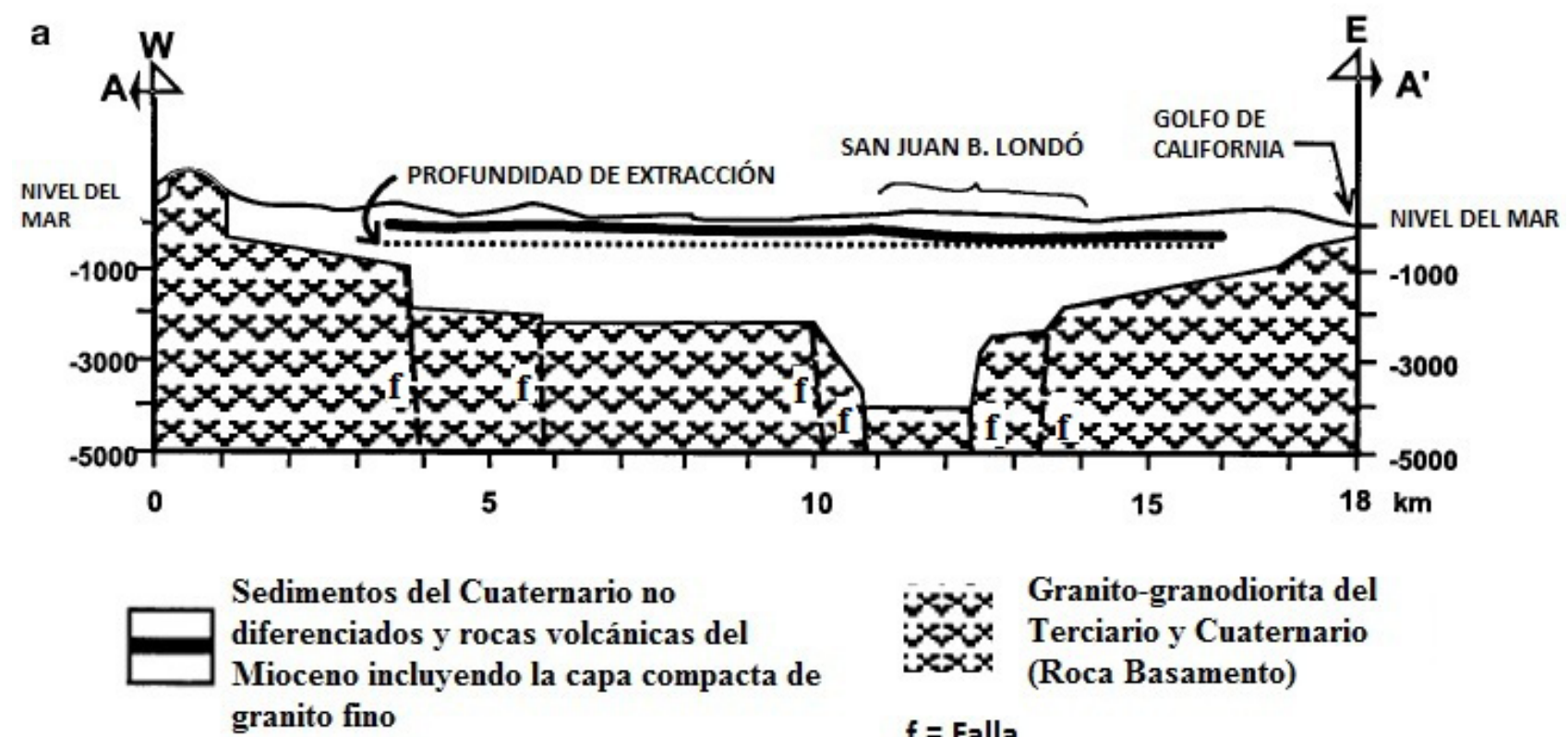

Figura 2. Sección geológica de San Juan B. Londó que muestra el área de extracción de agua subterránea.

(Formación Comondú) con una amplia distribución geográfica y gran espesor (> $3000 \mathrm{~m})$. Sus condiciones hidráulicas, dependiendo del sitio son libres, confinadas o semi-confinadas. Los pozos (con caudal entre 11 y $221 \mathrm{~s}^{-1}$ ) usualmente penetran sólo los primeros 20-80 m de este acuífero y terminan en toba, sedimentos y flujos de lava. Este acuífero está cubierto en lugares por la capa de arcilla compacta reportándose condiciones hidráulicas "semiconfinadas" que bien pueden estar ligadas a la respuesta ascendente al extraer agua termal. La falta de evidencia de subsidencia como de reporte de fracturas en el suelo sugieren que esta arcilla tiene baja compresibilidad. Así, la inferida baja conductividad hidráulica vertical y la baja porosidad de esta capa posiblemente restringen su aporte como semi-confinante y es posible que el caudal de esta fuente (pozo de extracción) en el área sea mínimo.

Debido a que el área de estudio está a unos $250 \mathrm{~km}$ de distancia de la zona hidrotermal más cercana, y como no hay géiseres y fuentes hidrotermales con fluido magmático en la vecindad, sugiere que el agua subterránea local no sea afectada por este tipo de fuente, ni en su química ni en su temperatura. Se carece de información sobre la temperatura o química del agua subterránea extraída con anterioridad; sin embargo, los usuarios reportan (en Carrillo-Rivera, 2000) que se ha incrementado la temperatura del agua extraída. En este trabajo se reporta que el agua subterránea tiene alta temperatura $\left(29.0-46.5^{\circ} \mathrm{C}\right)$, conductividad eléctrica de 1724 - $4300 \mu \mathrm{S} / \mathrm{cm}$, y concentración de B $(1.8-9.9 \mathrm{mg} / \mathrm{l})$, F $(0.3-3.4 \mathrm{mg} / \mathrm{l})$ y Na $(283.3-436.5 \mathrm{mg} / \mathrm{l})$, características que consideradas en el contexto hidrogeológico, sugieren que un $70 \%$ del agua obtenida en un pozo tiene una firma diferente a aquella de un flujo local (Carrillo-Rivera, 2000), indicando la inducción de flujos de tipo intermedio hacia los pozos de extracción. Comportamiento reportado para partes de México central donde se tienen condiciones hidrogeológicas similares (Carrillo-Rivera et al., 1996; Molina-Maldonado, 1997; Carrillo-Rivera, 2000).

Reportes confiables del caudal de agua subterránea extraída en el tiempo son escasos pese al marcado desarrollo y aumento poblacional. En general, la extracción de agua subterránea en el área se ha acrecentado, y sólo hay algunos datos sobre San Juan B. Londó y el uso agrícola con una extracción de $0.37 \mathrm{~m}^{3} / \mathrm{s}$ (fines de la década de los 70) y de $0.39 \mathrm{~m}^{3} / \mathrm{s}$ (para 1985) (Instituto de Geofísica, 1986). La extracción en la década de los 70 incorporó un abatimiento de $6.5 \mathrm{~m} / \mathrm{mes}$, y para 1985 de $0.7 \mathrm{~m} / \mathrm{mes}$; esto puede sugerir cambio en las condiciones de extracción de confinadas a libres (Instituto de Geofísica, 1986) o inducción de agua termal de menor densidad (Carrillo-Rivera y Cardona, 2008).

El Acuífero Principal surte de agua potable a las ciudades de Loreto y Nopoló (CNA, 1991). El agua circula horizontalmente por estos materiales granulares a una velocidad promedio de $24 \mathrm{~m} /$ año (porosidad $\approx 10^{-1}$, conductividad hidráulica horizontal $\approx 10^{-4} \mathrm{~m} / \mathrm{s}$; gradiente hidráulico horizontal, $\left.\approx 7.6 \times 10^{-4}\right)$ (CONAGUA, 2006).

La profundidad al nivel estático es de $20 \mathrm{~m}$ (alrededor y al O del poblado de San Juan B. Londó) y $50 \mathrm{~m} \mathrm{(al} \mathrm{S}$ de este poblado) donde se presenta la profundidad mayor (CONAGUA, 2006). Este estudio considera que el Grupo Salada y el basamento granítico permiten el flujo regional de agua por fracturas y fallas, el cual se manifiesta en 
manantiales termales submarinos y en los (pocos) reportados en la línea de costa (Prol-Ledesma et al., 2007). La recarga se tiene principalmente en la Sierra de La Giganta y se considera que la descarga se realiza por flujos locales hacia el material granular que forma la planicie costera, y por flujos de mayor jerarquía (intermedio y regional) que descargan hacia el mar en ambas vertientes.

\section{Material y Métodos}

Los datos hidrogeoquímicos utilizados corresponden fundamentalmente al resultado del muestreo realizado en el área de Loreto en los meses de marzo y mayo de 2009. También se tomaron muestras de dos sitios fuera del área de estudio, con la finalidad de sustentar estos análisis buscando el mayor número de conceptos de explicación a los procesos hidrogeoquímicos que ocurren en el área de estudio.

Se obtuvieron un total de 20 muestras. Las muestras 10-15 (de los pozos CNA3, CNA8, CNA4, San Nicolás, CNA6, CNA15), fueron tomadas en pozos (Figura 2) que usualmente realizan una intensa extracción (uso agrícola) y captan el Acuífero Principal en San Juan B. Londó. La muestra 19 (manantial Juncalito) fue tomada en la cercanía de la costa y corresponde con agua del Acuífero Principal en el área de Loreto; la muestra 20 (manantial hidrotermal Santispac) es del Municipio de Mulegé y fue tomada cerca de la línea de costa. Las muestras 1-9 y 16-18 fueron tomadas en la parte alta de la Sierra de La Giganta. Los datos de referencia (Tabla 3) reportados en Prol-Ledesma et al. (2007) corresponden a muestras de agua termal, manantiales submarinos y agua de mar.

Se midieron in situ en cada sitio, la temperatura, el pH, oxígeno disuelto, potencial redox (Eh) y conductividad eléctrica mediante equipos portátiles precalibrados en laboratorio y calibrados en campo (Tabla 1). Estas mediciones se realizaron en campo con el propósito de adquirir información confiable rápidamente, además de tener un control de referencia adecuado a las mediciones en laboratorio.

La determinación de alcalinidad total $\left(\mathrm{HCO}_{3}^{-} \mathrm{y} \mathrm{CO}_{3}{ }^{2-}\right)$ fue también efectuada en campo mediante el método de Gran (Cardona, 2003). En cada sitio se tomaron 5 botellas de agua en envases de polietileno con capacidad de $60 \mathrm{ml}$; las cuales fueron lavadas previamente con una solución de ácido clorhídrico al $10 \%$ y enjuagadas perfectamente con agua destilada (Armienta et al., 1997). El contenido de la botella para el análisis de metales pesados se filtró con una membrana de acetato de celulosa con abertura de $0.45 \mu \mathrm{m}$ para remover las partículas suspendidas de arcilla e hidróxidos de hierro y manganeso coloidales. Posteriormente, se le añadió 10 gotas de ácido nítrico de alta pureza llevando la solución a un $\mathrm{pH}$ de $\approx 2$ para preservar las especies disueltas. Para su transporte se mantuvieron en hielo (APHA-AWWA-WPCF, 1989) hasta el análisis correspondiente. Los macro y micro componentes fueron determinados mediante ICP-MS (Espectrometría de Emisión Atómica por Plasma acoplado a Espectrometría de Masas), en el laboratorio de la Universidad Autónoma de San Luis Potosí, México y Actlabs, Ontario, Canadá.

La calidad de los datos químicos de componentes mayores fue verificada mediante balance iónico y por la comparación entre la conductividad eléctrica real y la teórica (en ambos casos el error aceptado fue menor de $10 \%$ ). Para ello, se utilizó el algoritmo del programa HIDROGEOQUIM (Fagundo et al., 2005). Aplicando

Tabla 1. Mediciones en campo y análisis químicos de componentes mayores de las muestras en el área de Loreto B. C. S. Las concentraciones están en mg/l.

\begin{tabular}{|c|c|c|c|c|c|c|c|c|c|c|c|c|c|c|c|c|}
\hline No & $\mathrm{T}$ & $\mathrm{pH}$ & $\mathrm{Eh}(\mathrm{mV})$ & $\mathrm{O}_{2}$ & $\mathrm{CE}(\mu \mathrm{S} / \mathrm{cm})$ & $\mathrm{CO}_{2}$ & $\mathrm{HCO}_{3}$ & $\mathrm{Cl}^{-}$ & $\mathrm{SO}_{4}^{2-}$ & $\mathrm{NO}_{3}^{-}$ & $\mathrm{Ca}^{2+}$ & $\mathrm{Mg}^{2+}$ & $\mathrm{Na}^{+}$ & $\mathrm{K}^{+}$ & $\mathrm{SiO}_{2}$ & TDS \\
\hline 1 & 26.3 & 6.88 & 122 & 3.9 & 383 & 92.8 & 290.4 & 44 & 10.7 & 12.8 & 71 & 11.4 & 278 & 0.82 & 66 & 719 \\
\hline 2 & 21.8 & 8.47 & 143 & nd & 380 & 2.4 & 313.5 & 66.5 & 13.5 & 0.8 & 55 & 15.3 & 290 & 0.73 & 66 & 755 \\
\hline 3 & 24.9 & 7 & 84 & 2 & 602 & 45.7 & 298.7 & 50.2 & 9.3 & 11 & 59 & 23.7 & 54 & 0.61 & 66 & 506 \\
\hline 4 & 26.8 & 7.31 & 94.5 & 6.6 & 583 & 19.1 & 261.6 & 47.9 & 8.1 & 13.6 & 49 & 25.4 & 43 & 0.99 & 66 & 449 \\
\hline 5 & 21.9 & 8.29 & 105 & 6.6 & 536 & 1.9 & 226.4 & 25.6 & 6.6 & 12.6 & 33 & 24.1 & 38 & 2.24 & 66 & 369 \\
\hline 6 & 26.5 & 7.82 & 46 & 4.3 & 590 & 5.7 & 238.1 & 31 & 8.2 & 15.2 & 37 & 26.1 & 48 & 2.89 & 66 & 407 \\
\hline 7 & 26 & 8.85 & -0.4 & 6.2 & 590 & 5.7 & 253.8 & 33.1 & 7.3 & 13.8 & 37 & 26 & 41 & 1.94 & 66 & 414 \\
\hline 9 & 24.7 & 7.13 & 96 & 3.6 & 614 & 12.3 & 35.1 & 67.8 & 13.5 & 9.7 & 60 & 18.5 & 277 & 0.83 & 78 & 482 \\
\hline 10 & 29.3 & 7.59 & 187 & 3.5 & 961 & 10.2 & 283 & 341 & 99.7 & 23.8 & 38 & 33.4 & 366 & 4.97 & 78 & 1190 \\
\hline 11 & 28.5 & 7.42 & 163 & 3.7 & 852 & 14.6 & 280.6 & 268 & 105 & 17.5 & 43 & 24.4 & 285 & 0.55 & 72 & 1024 \\
\hline 12 & 27.6 & 7.71 & 179 & 2.9 & 1188 & 10 & 363.6 & 460 & 114 & 21.1 & 28 & 25.2 & 520 & 7.98 & 72 & 1540 \\
\hline 13 & 29.4 & 7.17 & 117 & 2.8 & 890 & 32.9 & 361.1 & 273 & 77.8 & 35.5 & 61 & 36.6 & 265 & 5.56 & 72 & 1116 \\
\hline 14 & 31.9 & 7.18 & 154 & 3.9 & 1075 & 19.5 & 226.9 & 435 & 103 & 26.6 & 102 & 53.8 & 274 & 1.88 & 84 & 1223 \\
\hline 15 & 28.8 & 7.15 & 124 & 5.1 & 1175 & 25 & 270.8 & 508 & 109 & 32.7 & 140 & 69 & 257 & 1.9 & 84 & 1388 \\
\hline 16 & 21.9 & 7.5 & 178 & 2.3 & 907 & 3.7 & 43.9 & 111 & 16.2 & 0.1 & 73 & 35.6 & 90 & 1.13 & 84 & 371 \\
\hline 18 & 28 & 7.27 & 72.2 & 5 & 639 & 3.5 & 24.4 & 62.2 & 13.3 & 24 & 42 & 4.4 & 94 & 0.67 & 84 & 265 \\
\hline 19 & 26 & 7 & 191 & 3.9 & 1616 & 85.5 & 617.3 & 735 & 56.8 & 22.9 & 312 & 71.4 & 422 & 1.28 & 84 & 2239 \\
\hline 20 & 30.1 & 7.13 & 98 & 3.6 & 10418 & 2.7 & 61.7 & 14000 & 631 & 2.2 & 425 & 177.9 & 1569 & 262 & 720 & 17209 \\
\hline
\end{tabular}

Muestras: 1- Las Parras (M); 2- San Javier Represo (M); 3- Santa Rosa (M); 4- Santa Rosa (M) 2; 5- San José Comondú (M); 6- Comondú 2 (M); 7Comondú 3 (M); 8- La Purísima (M); 9- San Javier (M); 10- CNA 3 (P); 11- CNA 8 (P); 12- CNA4 - Nantra Bay (P); 13- San Nicolás (M); 14- CNA6 (P); 15- CNA15 (P); 16- Santo Domingo (M); 17- Naocojoa Chico (M); 18- Naocojoa Grande (M); 19- Juncalito (M); 20- Santispac (MT). M: manantial; P: pozo; MT: manantial termal. $\mathrm{T}=\mathrm{Temp} .{ }^{\circ} \mathrm{C}$. 
este programa se calculó además el contenido de $\mathrm{CO}_{2}$ en equilibrio del agua. Para la clasificación de datos se utilizó el método de Kurlov (Fagundo, 1996), el cual toma en consideración para la clasificación los iones que pasan de un $20 \%$ de meq/l. La utilidad de este método se debe a que los patrones hidrogeoquímicos (expresados en términos de relación numérica de número entero entre 1 y 8 ; Tabla3), se calculan dividiendo por 10 el porcentaje de meq/1 de aniones y cationes.

Los patrones hidrogeoquímicos y procesos geoquímicos que explican el origen de la composición química de las aguas se determinó mediante el sistema informático MODELAGUA (Fagundo-Sierra et al., 2001), basado en modelos de reconocimiento de patrones, balance de masa y de mezcla de aguas. El uso de este programa permitió considerar la posibilidad de que, durante la trayectoria del flujo del agua en estudio, haya ocurrido variación de concentración (i.e. evapotranspiración); en el caso de gases no se considera este factor. Cuando se definió que la composición de una muestra fue resultado de mezcla de dos grupos, se calculó el delta iónico, lo cual permite conocer la proporción de mezcla, a partir de un ión conservativo. Como tal, se tomó el ion $\mathrm{Cl}^{-}$, ya que no se modifica en los procesos de interacción agua-roca.

\section{Resultados y discusión}

La composición química del agua subterránea en el área de estudio está determinada en parte por procesos de interacción agua-roca. Sin embargo, en la planicie de San Juan B. Londó existe una intensa extracción de agua subterránea para fines agrícolas (CONAGUA, 2006). Los resultados sugieren que intervienen otros procesos, como el ascenso de flujos intermedios o regionales y fuentes de salinidad que están determinando la calidad del agua en esta zona.

Los parámetros medidos en campo y los resultados de los análisis químicos para los componentes mayores son presentados en la Tabla 1 y los componentes menores son presentados en la Tabla 2.

\subsection{Grupos de agua y patrones hidrogeoquímicos}

Con base en el criterio que considera la determinación de los patrones hidrogeoquímicos (Fagundo, 1998) se determinaron 7 grupos de agua (Tabla 3). Como representación gráfica se utilizaron los diagramas de Stiff (1951) para mostrar los diferentes grupos de agua (Figura 4); también se incluyen el correspondiente patrón hidrogeoquímico. Esto último se determinó a partir del valor medio de la composición química del agua de cada grupo.

Con base en estos resultados (Tabla 3) se analizan las características hidrogeoquímicas de cada grupo de agua:

Grupo 1, está constituido por 2 muestras cuya composición es de tipo bicarbonatada clorurada sódica,
Tabla 2. Resultados de los análisis químicos de componentes menores de las muestras en el área de Loreto B. C. S. Las concentraciones están en $\mu \mathrm{g} / \mathrm{l}$.

\begin{tabular}{ccccccccc}
\hline No & G & $\mathrm{F}$ & $\mathrm{Br}$ & $\mathrm{I}$ & $\mathrm{As}$ & $\mathrm{B}$ & $\mathrm{Li}$ & $\mathrm{Sr}$ \\
\hline 1 & 1 & 6430 & 164.6 & 62.8 & 1.8 & 170.6 & 5.7 & 114.8 \\
2 & 1 & 30 & 243.4 & 44 & 1.1 & 206.6 & 2.1 & 84.8 \\
3 & 2 & 40 & 111.4 & 51.4 & 1.3 & 100.2 & 7.1 & 90.1 \\
4 & 2 & 100 & 100.6 & 52.1 & 1.3 & 70.8 & 5 & 239.1 \\
5 & 3 & 70 & 65.7 & 37.9 & 1.6 & 96.7 & 4.1 & 350.3 \\
6 & 3 & 110 & 74.2 & 36.2 & 1.7 & 97.3 & 5 & 373.5 \\
7 & 3 & 160 & 76.8 & 39.7 & 1.5 & 101 & 5.2 & 362.9 \\
8 & 3 & 270 & 149.8 & 68.1 & 2.2 & 348.3 & 13.1 & 352.1 \\
9 & 4 & 40 & 232.2 & 58.7 & 1.1 & 182.1 & 4.9 & 99 \\
10 & 4 & 170 & 653.7 & 129.1 & 41.6 & 1112.6 & 68.4 & 408.2 \\
11 & 4 & 200 & 483.3 & 129.6 & 5.2 & 2277.8 & 22 & 115 \\
12 & 4 & 90 & 792.5 & 145.5 & 123.9 & 1019.6 & 60 & 299.4 \\
13 & 4 & 50 & 566.9 & 104.1 & 9.3 & 625.8 & 29.7 & 221 \\
14 & 5 & 25 & 876.7 & 96.6 & 11.1 & 1515.7 & 37.6 & 698.7 \\
15 & 5 & 50 & 1065.5 & 67.6 & 5.5 & 1259.2 & 49.7 & 349.3 \\
16 & 5 & 30 & 209.8 & 47.1 & 1.9 & 206.3 & 4 & 243.4 \\
17 & 5 & 80 & 173.3 & 65.3 & 1.3 & 188.9 & 7.4 & 83.8 \\
18 & 5 & 120 & 119.1 & 55.1 & 1.1 & 185.7 & 5.7 & 91.8 \\
19 & 5 & 50 & 1268.9 & 155.8 & 6 & 485.3 & 12.9 & 297.3 \\
20 & 6 & 500 & 16937.2 & 348.8 & 149.4 & 3942 & 2066 & 31790.3 \\
\hline
\end{tabular}

1- Las Parras (M); 2- San Javier Represo (M); 3- Santa Rosa (M); 4- Santa Rosa (M) 2; 5- San José Comondú (M); 6- Comondú 2 (M); 7- Comondú 3 (M); 8- La Purísima (M); 9- San Javier (M); 10- CNA 3 (P); 11- CNA 8 (P); 12- CNA4 - Nantra Bay (P); 13- San Nicolás (M); 14- CNA6 (P); 15- CNA15 (P); 16- Santo Domingo (M); 17- Naocojoa Chico (M); 18- Naocojoa Grande (M); 19- Juncalito (M); 20- Santispac (MT). M: manantial; P: pozo; MT: manantial termal. G: Grupo.

Tabla 3. Patrones hidrogeoquímicos (Fagundo, 1998), tipos de agua y factor de concentración (FC) de cada una de las muestras de agua en el área de Loreto B. C. S.

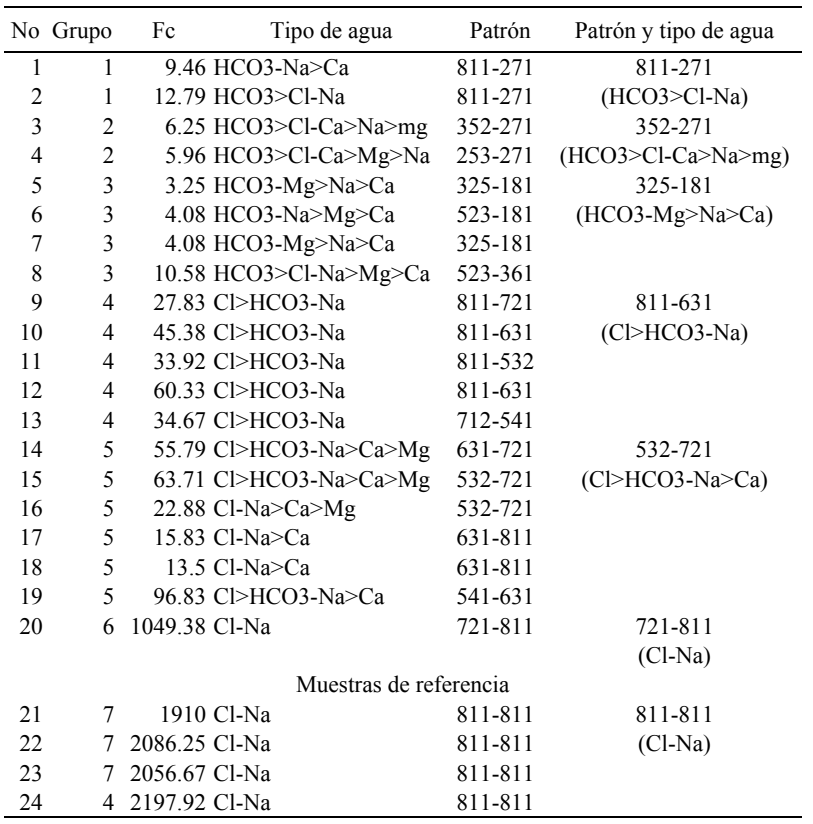

Muestra: 1- Las Parras; 2- San Javier Represo; 3- Santa Rosa; 4- Santa Rosa 2; 5-San José de Comondú; 6- Comondú 2; 7-Comondú 3; 8- La Purísima; 9- San Javier; 10- CNA3; 11- CNA8; 12- CNA4 (Nantra Bay); 13- San Nicolás; 14-CNA6; 15-CNA15; 16- Santo Domingo; 17 - Naocojoa 1; 18 Naocojoa 2; 19- Juncalito; 20- Santispac; 21- BC1 Manantial submarino *; 22- BC4 Manantial submarino *; 23- BC6 Manantial submarino *; 24- BC9 Agua de mar BC *. FC: Factor de concentración del Cl- con respecto al agua de lluvia (Arizona EUA). *: Datos tomados de Prol-Ledesma et al. (2007). 
patrón hidrogeoquímico 811-271 (Tabla 3). Su rasgo distintivo es $\mathrm{Na}^{+}>\mathrm{Ca}^{2+}$, siendo despreciable el contenido de $\mathrm{Mg}^{2+}$, lo que indica el predominio de contacto con feldespato tipo plagioclasa sódica (albita-oligoclasa) así como disolución equivalente a la presencia de halita. El rasgo distintivo de la segunda muestra que compone este grupo es $\mathrm{HCO}_{3}^{-}>\mathrm{Cl}^{-}$, siendo despreciable el contenido de $\mathrm{Ca}^{2+}$. La concentración de sales totales disueltas varía (STD) entre 719 y $755 \mathrm{mg} / \mathrm{l}$.

Grupo 2, está formado por dos muestras de agua de tipo bicarbonatada clorurada cálcica sódica magnésica, patrón hidrogeoquímico 352-271 (Tabla 3). En este grupo se aprecia alto contenido de $\mathrm{Na}^{+}$y $\mathrm{Ca}^{2+}>\mathrm{Mg}^{2+}$. La segunda muestra del grupo presenta un tipo de agua bicarbonatada clorurada cálcica magnésica sódica, ambas son típicas de la andesina y biotita así como disolución equivalente a la presencia de halita. El contenido de STD varía entre de 449-506 mg/l.

Grupo 3, donde se agrupan 4 muestras, con facies hidrogeoquímicas bicarbonatada magnésica sódica cálcica, principalmente. Su patrón hidrogeoquímico es 325-181 (Tabla 3). En este grupo prevalece $\mathrm{Na}^{+}$, pero también contiene $\mathrm{Mg}^{2+}>\mathrm{Ca}^{2+}$, lo que sugiere que el agua adquiere su composición por intemperismo y disolución equivalente a la presencia de halita así como por un mineral más rico en magnesio que en los casos anteriores, posiblemente olivino o biotita, junto a la plagioclasa andesina. La cantidad STD varía entre 369 y $502 \mathrm{mg} / \mathrm{l}$.

Grupo 4, se integra por 5 muestras de composición clorurada bicarbonatada sódica que tienen un patrón hidrogeoquímico 811-631 (Tabla 3). Esta agua tiene un patrón $\mathrm{Na}^{+}>\mathrm{Cl}^{-}$, lo que pudiera deberse a procesos de intercambio iónico de tipo directo entre $\mathrm{Na}^{+} \mathrm{y} \mathrm{Ca}^{2+}$. Los valores de STD son entre 482 y $1540 \mathrm{mg} / \mathrm{l}$.

Grupo 5, está formado por 6 muestras cuya composición química es clorurada bicarbonatada sódica, en algunos casos cálcica (19) o cálcica magnésica, como en las muestras 14 y 15; en otros sódico cálcica como en las muestras 17 y 18, su patrón hidrogeoquímico es 532-721 (Tabla 3). A diferencia del patrón anterior, el $\mathrm{Cl}^{-}>\mathrm{Na}^{+}$, posiblemente debido a procesos de intercambio iónico inverso entre $\mathrm{Na}^{+}$ $\mathrm{y} \mathrm{Ca}^{2+}$. El contenido de STD de estas muestras es entre 371 y $2239 \mathrm{mg} / \mathrm{l}$.

Grupo 6, lo forma una muestra de agua termal, de composición clorurada sódica con un patrón hidrogeoquímico 721-811 (Tabla 3); su contenido de STD es 17209 mg/l.

Grupo 7, está constituido por agua de manantiales termales submarinos y el agua de mar (datos tomados de Prol-Ledesma et al., 2007). Este grupo de agua clorurada sódica, con patrón hidrogeoquímicos 811-811 (Tabla 3). El contenido de STD se encuentra entre 24137 y $35402 \mathrm{mg} / \mathrm{l}$.

En las muestras de los grupos 4 y 5 , se aprecia mejor la relación entre el patrón hidrogeoquímico, el tipo de litología y los procesos geoquímicos modificadores de la composición debida a la interacción agua-roca, tales como procesos de intercambio iónico. Para apreciar mejor la relación entre la composición química del agua y la litología por donde circula se utilizó el modelo computacional MODELAGUA y se le extrajo a los datos, el contenido de $\mathrm{NaCl}, \mathrm{Ca}^{2+}$ y $\mathrm{Na}^{+}$que pudiera estar siendo aportado por procesos de mezcla debido al intercambio iónico. De esta manera se obtuvo un nuevo patrón hidrogeoquímico que nos permitió analizar con mayor claridad los procesos que determinan la composición química del agua subterránea en el área de estudio. Estos son:

El patrón del Grupo 1 es típico de agua en contacto con plagioclasa sódica (albita, oligoclasa) y biotita; el patrón del Grupo 2 el de un agua que ha disuelto plagioclasa sódico cálcica (andesina) y biotita; el patrón del Grupo 3 muestra mayor contenido de $\mathrm{Mg}^{2+}$ que de $\mathrm{Ca}^{2+}$, posiblemente porque el agua circula en un terreno con alto contenido de minerales constitutivos de rocas máficas como basalto (olivino), además de plagioclasa tipo andesina; el patrón del Grupo 4 (excluyendo aporte de $\mathrm{NaCl}$ de halita) es propio de agua que circula por minerales con alto contenido de $\mathrm{Na}^{+}$y similar contenido de $\mathrm{Ca}^{2+} \mathrm{y} \mathrm{Mg}^{2+}$, posiblemente diversos minerales como plagioclasa sódico-cálcica (oligoclasa, andesina) y biotita, aunque parte del $\mathrm{Na}^{+}$del patrón original podría deberse al aporte por intercambio iónico directo; el patrón del Grupo 5 (excluyendo el aporte de $\mathrm{NaCl}$ de halita), es parecido al del Grupo 2 en cuanto a la relación $\mathrm{Ca}^{2+} / \mathrm{Mg}^{2+}$, pero con déficit de $\mathrm{Na}^{+}$con respecto al $\mathrm{Cl}^{-}$(patrón original), lo cual pueda deberse a un proceso de intercambio iónico inverso. El patrón del agua del manantial termal cercano a la costa (Grupo 6) muestra una relación $\mathrm{Ca}^{2+} / \mathrm{Mg}^{2+}$ similar a la del Grupo 2 y 5 , pero con apreciable déficit de $\mathrm{Na}^{+}$. Por último, el patrón del Grupo 7, que incluyen los manantiales termales submarinos, si bien muestran más parecido al agua marina, se distingue en el agua de éstos una evolución hidrogeoquímica distinta evidente en elementos traza como Li, As $_{\text {total }}, \mathrm{B}^{-}, \mathrm{Br}, \mathrm{Sr}$ y I'-

Mediante el uso de modelos de balance de masa y mezcla de aguas, se procederá más adelante a interpretar, con mayor precisión aún los procesos geoquímicos que originan la composición química del agua en esta área de estudio.

\subsection{Distribución espacial de los patrones hidrogeoquímicos}

Al representar en un mapa los diagramas de Stiff correspondientes a cada una de las muestras (Figura 3) se identifica la distribución espacial de los patrones hidrogeoquímicos. Con esto se aprecia que los patrones hidrogeoquímicos típicos del agua del Grupo 1 se distribuyen en la parte septentrional de la porción E del área; los del Grupo 2, más al S de esta misma área; los del Grupo 3 en la parte $\mathrm{N}$ y central del área $\mathrm{O}$ del área; el patrón del agua termal (Grupo 6), se localiza al NE mientras que las aguas con mayor contenido de $\mathrm{Cl}^{-}$y $\mathrm{Na}^{+}$, en sitios con extracción agrícola (Grupos 5 y 6), se ubican al NO del área, excepto un manantial (Santo Domingo), ubicado en la parte más $\mathrm{S}$ del área. 


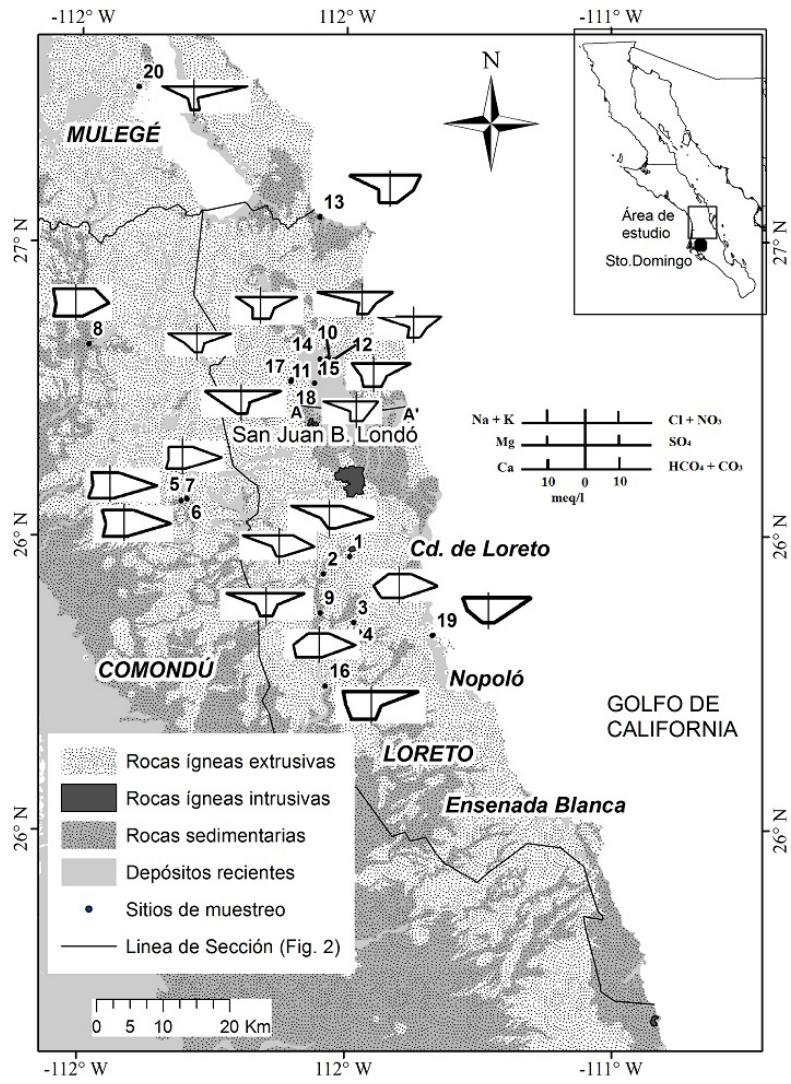

Figura 3. Distribución espacial de los patrones hidrogeoquímicos de muestras de agua en el área de estudio.
La variación en unidades logarítmicas de la concentración de algunos componentes mayores: $\mathrm{Cl}^{-}, \mathrm{Na}^{+}, \mathrm{K}^{+}$y $\mathrm{SO}_{4}{ }^{2-}$ (mg/l); y de componentes menores: $\mathrm{Br}, \mathrm{As}, \mathrm{B}, \mathrm{Li}$ y $\mathrm{Sr}(\mu \mathrm{m} / \mathrm{l})$ de las muestras obtenidas en manantiales y pozos del área de estudio, así como de muestras de manantiales y agua de mar compilados de la literatura (Prol-Ledesma et al., 2007) puede apreciarse mejor en la Figura 4. Los datos están ordenados aproximadamente, de menor a mayor, con respecto al contenido de $\mathrm{Cl}$. Esto con la finalidad de representar mejor el aumento en el contenido de algunos componentes. El resultante responde en relación con el incremento del $\mathrm{Cl}^{-}$. De esta manera es posible mostrar los resultados que indican que los pozos sometidos a extracción agrícola y algunos manantiales incrementan su contenido en componentes que, al parecer proceden de flujos de carácter intermedio o regional (agua termal) como $\mathrm{As}_{\text {total }}$ y Li, más que de origen marino. Esto parece estar también respaldado por los valores de temperatura del agua muestreada, la cual es definitivamente cuatro grados mayor a la temperatura media ambiental del área de estudio (muestras 6, 7, 8, 10, 11, $12,13,14,15,18)$. En el caso de los pozos, el que presenten alto contenido de elementos traza se debe específicamente al ascenso de agua de flujo de tipo intermedio o regional por efecto de la extracción; este proceso ha sido claramente identificado en rocas similares en el Centro de México (Carrillo-Rivera et al., 1996).

Si se considera la relación de concentración entre

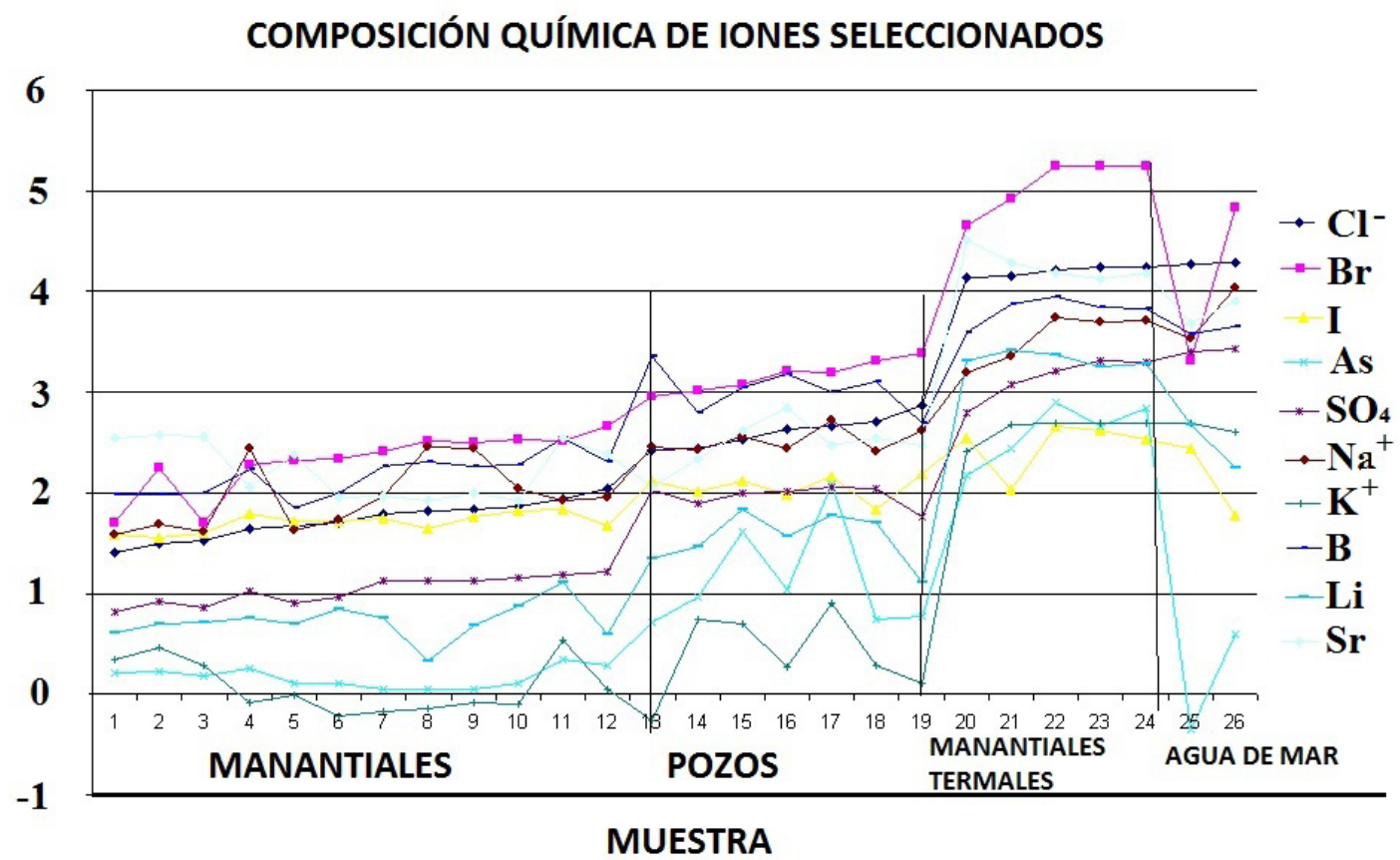

Figura 4. Variación de la concentración de $\mathrm{Cl}^{-}$y $\mathrm{SO}_{4}{ }_{4}^{2-}(\log \mathrm{mg} /$ eje y) y Br, As, B, Li y $\mathrm{Sr}(\log \mu \mathrm{g} / \mathrm{l})$ en manantiales, pozos, manantiales termales y agua de mar. 1- Manantiales: San José Comondú; 2- Comondú 2, 3- Comondú 3, 4- Las Parras; 5- Santa Rosa 2; 6- Santa Rosa; 7- Naocojoa Grande; 8- San Javier Represo; 9- San Javier; 10- Naocojoa Chico; 11- La Purísima; 12- Santo Domingo; 14- San Nicolás; 19-Juncalito; pozos 13- CNA8;15-CNA3, 16- CNA6, 17-CNA4; 18-CNA8; manantial termal 20-21*- Santispac; manantiales submarinos 22- BC1*; 23-BC4*; 24-BC6*; agua marina 25-*; 26- **). *: Datos tomado de Prol-Ledesma et al. (2007); **: Datos tomados de Drever (1982). 
el componente estudiado y la concentración del mismo componente correspondiente a la muestra de menor contenido de $\mathrm{Cl}^{-}$(San José de Comondú), el aumento de concentración (con relación al $\mathrm{Cl}^{-}$) que experimentan los iones en el agua de los pozos es notable. Esta concentración se obtiene de la división del contenido de $\mathrm{Cl}^{-}$del agua subterránea entre el agua de lluvia.

Esta magnitud es mucho mayor que la que experimentan los manantiales, con excepción de San Nicolás y Juncalito que también es alta (Tabla 4). Esto puede deberse a la cercanía con el agua de mar. En el agua de los manantiales termales esta relación de aumento de concentración es muy elevada debido al largo recorrido subterráneo así como por el aumento de temperatura que el agua adquiere durante su recorrido y la posible presencia de agua congénita marina aún presente en su recorrido hacia la descarga.

4.3. Factor de concentración (FC) del agua subterránea respecto a la precipitación

El factor de concentración cuantifica los procesos de concentración y puede determinarse a partir de la selección de un ión conservativo. Si este es igual a 1 significa que no se producen fenómenos de concentración. Este ión es un compuesto que no participa en ninguno de los procesos geoquímicos presentes en la región y que por tanto la diferencia de masa entre el valor que presenta el mismo en la muestra y el que presenta en la referencia se debe solamente a procesos de concentración (Schoeller, 1960). Teniendo en cuenta que el $\mathrm{Cl}^{-}$es un ión conservativo, su incremento en el agua, comparado con el de la precipitación en el área, puede tomarse como un indicador aproximado del proceso de evapotranspiración (Schoeller, 1960). El uso de este método hidrogeoquímico simple de estimación de la recarga al agua subterránea se ha aplicado con efectividad en algunas regiones áridas, donde la humedad del suelo es difícil de medir (Edmunds et al., 1988).

En el presente trabajo se tomó la concentración de agua de lluvia más cercana para la región, que correspondió a Arizona, E.U.A. La concentración de $\mathrm{Cl}^{-}$del agua subterránea en el área de Loreto con respecto al contenido de este ión en el agua de lluvia varía entre: 9.5 - 12.8 (agua

Tabla 4. Reconcentración de componentes seleccionados

\begin{tabular}{ccccccccccc}
\hline $\begin{array}{c}\text { Grupo de } \\
\text { muestras }\end{array}$ & $\begin{array}{c}\text { Cloruro } \\
\text { medio }\end{array}$ & $\mathrm{Cl}$ & $\mathrm{Br}$ & $\mathrm{i}$ & $\mathrm{As}$ & $\mathrm{Na}$ & $\mathrm{K}$ & $\mathrm{B}$ & $\mathrm{Li}$ & $\mathrm{Sr}$ \\
\hline $\mathrm{I}$ & 38.6 & 1.5 & 3 & 1 & 1.2 & 2.2 & 0.7 & 1.1 & 1.3 & 0.7 \\
$\mathrm{II}$ & 77.9 & 3 & 6.8 & 2 & 1.5 & 4.1 & 0.6 & 2.3 & 1.5 & 0.5 \\
$\mathrm{III}$ & 431.4 & 16.9 & 30.9 & 3 & 18.1 & 9 & 1.6 & 12.3 & 9.8 & 1 \\
$\mathrm{IV} *$ & 1600 & 625 & 2625.6 & 9 & 296.2 & 102.5 & 200.7 & 70.6 & 521.6 & 53.9 \\
$\mathrm{~V} * *$ & 19025 & 743.2 & 690.3 & 4 & 1.4 & 187.2 & 201.3 & 43.2 & 79.5 & 18.2 \\
\hline
\end{tabular}

Muestras: I-San José Comondú, Comondú 2, Comondú 3, Las Parras, Santa Rosa, Santa Rosa 2; II- Naocojoa Chico, Naocojoa Grande, San Javier Represo, San Javier, La Purísima, Santo Domingo; III- CNA3, CNA4, CNA5, CNA6, CNA15, San Nicolás, Juncalito; IV- Santispac, BC1, BC4, BC5, V-Agua de mar; *: *: Datos tomado de Prol-Ledesma et al. (2007); **: Estación meteorológica Arizona, EUA (2009) del Grupo 1); 5.9 - 6.3 (Grupo 2) y 3.3 - 10.6 (Grupo 3). Las muestras de agua de los grupos 4 y 5 , afectadas por actividad agrícola, y por el recorrido largo en el subsuelo del agua muestreada proponen que el $\mathrm{Cl}^{-}$tiende a concentrarse, por lo que la magnitud es mayor, con un rango que oscila entre 13.5 y 96.8. En general, estos valores de FC en el agua son coherentes con el carácter árido de Loreto donde la lluvia media anual es de $\approx 115 \mathrm{~mm}$ (Steinitz et al., 2005). La tabla 4 muestra el FC por grupo de agua. En regiones húmedas, como en la Sierra del Rosario en Cuba, se han determinado valores de FC del orden de 3.0 (Fagundo et al., 2000), mientras en otras regiones áridas de Cuba (Provincia de Las Tunas), donde el promedio de lluvia anual oscila entre 100 y $180 \mathrm{~mm}$, se obtuvieron valores de FC entre 27.2 y 45.3 (Zamora, 2008).

Esto es similar a lo encontrado en la región árida de Loreto en nuestro trabajo (Tabla 3). Las muestras fueron agrupadas por grupos de agua.

\subsection{Origen de la composición química del agua}

La selección de minerales constitutivos de las rocas por donde circuló el agua consideró información del referente geológico y aspectos discutidos en el análisis de patrones hidrogeoquímicos originales: plagioclasa (aporte de $\mathrm{Na}^{+} \mathrm{y}$ $\mathrm{Ca}^{2+}$ ), biotita (aporte de $\mathrm{Mg}^{2+}$ y algo de $\mathrm{K}^{+}$), olivino $\left(\mathrm{Mg}^{2+}\right)$, microclino $\left(\mathrm{K}^{+}\right)$, pirita (la oxidación de la pirita, mineral muy distribuido en la naturaleza podría aportar $\mathrm{SO}_{4}{ }^{2-}$ ), cuarzo $\left(\mathrm{SiO}_{2}\right)$, así como $\mathrm{CO}_{2}$ biogénico y el equilibrio $\mathrm{CO}_{2}-\mathrm{HCO}_{3}^{-}$. Para las aguas salinas, que experimentan déficit iónico de $\mathrm{Ca}^{2+}, \mathrm{Mg}^{2+}, \mathrm{Na}^{+}$y $\mathrm{K}^{+}$en el balance de masa, intervienen equilibrios relacionados con la calcita, la calcita-dolomita, e intercambio iónico entre $\mathrm{Ca}^{2+} \mathrm{y} \mathrm{Na}^{+}$; así como entre $\mathrm{Ca}^{2+}$ $\mathrm{y} \mathrm{K}^{+}$. Los procesos geoquímicos utilizados en este trabajo para explicar el origen de la composición química del agua se muestran en la Tabla 5 (Appelo y Postma, 1993).

El modelo de balance de masas aplicado para explicar el origen de la composición química del agua en los grupos con bajo contenido salino (1, 2 y 3 ) utilizó como muestra de referencia el agua de lluvia (Arizona, E.U.A.), mostrando que los principales procesos geoquímicos corresponden al aporte de $\mathrm{Na}^{+}$y $\mathrm{Ca}^{2+}$ por la albita-caolinita y la anortita respectivamente, entre los iones principales (Tabla 6). Para los grupos de agua con elevado contenido salino (4 y 5) se tomó como referencia la muestra del manantial Las Parras (para las muestras 9-18 y 20) y de Santa Rosa (para la muestra 19), como referencia de agua dulce. Como miembro extremo de la mezcla el manantial BC4 (Prol-Ledesma et al., 2007) por su alto contenido de $\mathrm{NaCl}$. Los resultados muestran las reacciones de intercambio iónico así como el aporte equivalente a la disolución de halita (Tabla 7).

Para seleccionar la muestra de referencia se consideró que de acuerdo con el tipo de patrón hidrogeoquímico del agua, los grupos 1, 2 y 3 de menor salinidad adquieren su composición mediante procesos de interacción agua-roca entre la lluvia y los minerales incluidos en la litología del 
Tabla 5. Principales reacciones químicas de los procesos geoquímicos que explican el origen de la composición química del agua.

\begin{tabular}{|c|c|c|}
\hline Mineral & Fórmula & Proceso geoquímico y formulación \\
\hline Halita & $\mathrm{NaCl}$ & 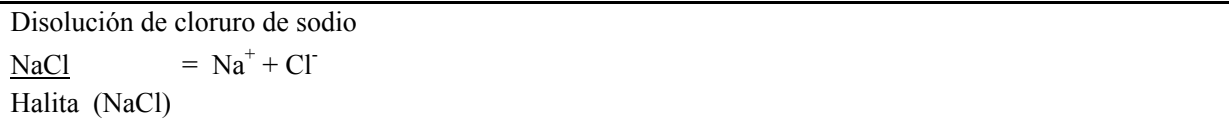 \\
\hline Calcita & $\mathrm{CaCO}_{3}$ & $\begin{array}{l}\text { Disolución - precipitación de calcita } \\
\mathrm{CO}_{2}+\mathrm{H}_{2} \mathrm{O}+\frac{\mathrm{CaCO}_{3}}{\text { Calcita }}=\mathrm{Ca}_{2+}+2 \mathrm{HCO}_{32-}\end{array}$ \\
\hline Biotita & $\mathrm{KMg}_{3} \mathrm{Al}_{2} \mathrm{Si}_{3} \mathrm{O}_{12} \mathrm{H}_{2}$ & $\begin{array}{l}\text { Meteorización de serpentinita } \\
14 \mathrm{CO}_{2}+15 \mathrm{H}_{2} \mathrm{O}+2 \frac{\mathrm{KMg}_{3} \mathrm{Al}_{2} \mathrm{Si}_{3} \mathrm{O}_{1} \mathrm{H}_{2}}{\text { Biotita }} \leftrightarrow 2 \mathrm{~K}^{+}+\underset{\text { Caolinita }}{6 \mathrm{Mg}^{2+}}+\underline{\mathrm{Al}_{2} \mathrm{Si}_{2} \mathrm{O}_{5}(\mathrm{OH})_{4}}+4 \mathrm{H} 4 \mathrm{SiO} 4\end{array}$ \\
\hline Olivino & $\mathrm{MgFe}\left(\mathrm{SiO}_{4}\right)$ & $\begin{array}{l}\text { Meteorización de olivino } \\
4 \mathrm{CO}_{2}+4 \mathrm{H}_{2} \mathrm{O}+\frac{\mathrm{MgFe}\left(\mathrm{SiO}_{4}\right)}{\text { Olivino }} \leftrightarrow \mathrm{Mg}^{2+}+\mathrm{Fe}^{2+} 4 \mathrm{HCO}_{3}^{-}+\mathrm{H} 4 \mathrm{SiO} 4\end{array}$ \\
\hline Plagioclasa & $\begin{array}{l}\left(x \mathrm{NaAlSi}_{3} \mathrm{O}_{8}^{+} \text {y }\right. \\
\left.\mathrm{CaAl}_{2} \mathrm{Si}_{2} \mathrm{O}_{8}\right)\end{array}$ & 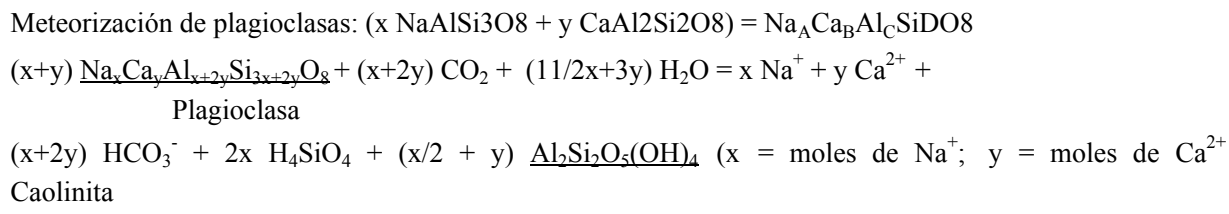 \\
\hline $\begin{array}{l}\text { Feldespato } \\
\text { potásico } \\
\text { (microclina) }\end{array}$ & $\mathrm{KAlSi}_{3} \mathrm{O}_{8}$ & $\begin{array}{l}\text { Meteorización de feldespato potásico (microclino) } \\
2 \underline{\mathrm{KAlSi}_{3} \mathrm{O}_{8}}+2 \mathrm{CO}_{2}+11 \mathrm{H}_{2} \mathrm{O}=2 \mathrm{~K}++2 \mathrm{HCO}_{3}^{-}+4 \mathrm{H}_{4} \mathrm{SiO}_{4}(\mathrm{l})+\underline{\mathrm{Al}_{2} \mathrm{Si}_{2} \mathrm{O}_{5}(\mathrm{OH})_{4}} \\
\text { Microclino } \quad \text { Caolinita }\end{array}$ \\
\hline Pirita & $\mathrm{FeS}_{2}$ & 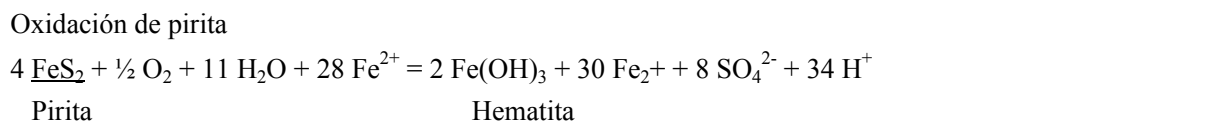 \\
\hline $\begin{array}{l}\text { Feldespato } \\
\text { potásico } \\
\text { (microclina) }\end{array}$ & $\mathrm{KAlSi}_{3} \mathrm{O}_{8}$ & $\begin{array}{l}\text { Meteorización de feldespato potásico (microclino) } \\
2 \underline{\mathrm{KAlSi}_{3} \mathrm{O}_{8}}+2 \mathrm{CO}_{2}+11 \mathrm{H}_{2} \mathrm{O}=2 \mathrm{~K}++2 \mathrm{HCO}_{3}^{-}+4 \mathrm{H}_{4} \mathrm{SiO}_{4}(\mathrm{l})+\underline{\mathrm{Al}_{2} \mathrm{Si}_{2} \mathrm{O}_{5}(\mathrm{OH})_{4}} \\
\text { Microclino Caolinita }\end{array}$ \\
\hline Pirita & $\mathrm{FeS}_{2}$ & $\begin{array}{l}\text { Oxidación de pirita } \\
4 \frac{\mathrm{FeS}_{2}}{\text { Pirita }}+1 / 2 \mathrm{O}_{2}+11 \mathrm{H}_{2} \mathrm{O}+28 \mathrm{Fe}^{2+}=2 \frac{\mathrm{Fe}(\mathrm{OH})_{2}}{\text { Hematita }}+30 \mathrm{Fe}^{2+}+8 \mathrm{SO}_{4}{ }^{2-}+34 \mathrm{H}^{+}\end{array}$ \\
\hline $\begin{array}{l}\text { Sulfhídrico - } \\
\text { Azúfre }\end{array}$ & $\mathrm{H}_{2} \mathrm{~S}-\mathrm{S}$ & $\begin{array}{l}\text { Reducción de sulfato } \\
2 \mathrm{CH}_{2} \mathrm{O}+\mathrm{SO}_{4}^{2-}=\mathrm{H}_{2} \mathrm{~S}+2 \mathrm{HCO}_{3}^{-} \\
\text {Materia orgánica } \\
\text { Formación de azúfre a partir de } \mathrm{H}_{2} \mathrm{~S} \\
\mathrm{H}_{2} \mathrm{~S}+\mathrm{O}_{2}=2 \mathrm{~S}+\mathrm{H}_{2} \mathrm{O}\end{array}$ \\
\hline $\mathrm{Ca}^{2+}-\mathrm{Na}+$ & $\mathrm{Ca}-\mathrm{NaR}_{2}$ & Intercambio iónico Ca-Na y $\mathrm{Ca}-\mathrm{K}$ \\
\hline $\mathrm{Ca}^{2+}-\mathrm{K}+$ & $\mathrm{Ca}-\mathrm{KR}_{2}$ & 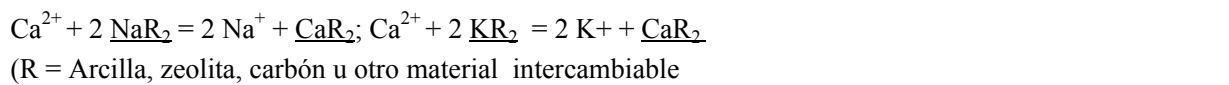 \\
\hline
\end{tabular}

terreno (Tabla 6). Los segundos, que corresponden a agua obtenida en pozo, más salina, que adquiere su composición química mediante un proceso combinado de interacción agua-roca entre la lluvia y medio por el que circula el agua así como de un proceso adicional que es el aporte de un flujo de mayor mineralización, posiblemente de tipo intermedio o regional, que es inducido a la zona de extracción de agua del pozo (Tabla 8). En ambos casos se aprecia el aporte de la disolución equivalente a la presencia de halita.

Como se mencionó anteriormente, una forma de interpretar el modo en que el agua adquiere su composición en el caso de las muestras con alto contenido salino es mediante procesos de balance de masa y mezcla con flujos de carácter intermedio o regional. En estos casos se observa la precipitación significativa de calcita, compensándose el contenido de $\mathrm{Ca}^{2+}$ adquirido mediante procesos de intercambio iónico entre $\mathrm{Na}^{+} \mathrm{y} \mathrm{Ca}^{2+}$. También intervienen procesos de intercambio iónico entre $\mathrm{Na}^{+} \mathrm{y} \mathrm{Ca}^{2+}$ así como entre $\mathrm{K}^{+} \mathrm{y} \mathrm{Ca}^{2+}$, oxidación de pirita o reducción de $\mathrm{SO}_{4}^{-} \mathrm{y}$ disolución y precipitación de $\mathrm{SiO}_{2}$. La tabla 8 muestra que el porcentaje de agua marina varía en la mezcla, en los manantiales entre 0.1 y $2.7 \%$, pero en el manantial 
termal Santispac alcanza un 64\%. La mezcla en este último manantial puede ser debida a que al estar en una oquedad sobre la línea de costa permite la entrada de agua de mar a la misma.

Para determinar el tipo de plagioclasa por la que circula el agua de las muestras pertenecientes a los Grupos 1, 2 y 3, se utilizó el aporte de $\mathrm{Na}^{+}$(albita) y $\mathrm{Ca}^{2+}$ (anortita) del agua.

Multiplicando la proporción de moles con que cada mineral (formado, precipitado o transformado) participa en los procesos geoquímicos de interacción agua-roca por el peso molecular de dicho mineral (mg/l), se puede determinar la masa transferida en proceso de intemperismo que dio origen a la composición química del agua (Appelo y Postma, 1993). En estos cálculos se utilizaron las siguientes expresiones: Halita $=58.5 \cdot \mathrm{Cl}^{-}$(halita); Plagioclasa $=274$ $* \cdot \mathrm{Na}^{+}$(albita) $+286 * \cdot \mathrm{Ca}^{2+}$ (anortita); Microclino $=290$ $* \mathrm{~K}^{+}$(microclino); Biotita $=(172.3) * 1 /{ }_{3} \mathrm{Mg}^{2+}$; Olivino $=$ $120 * \mathrm{Mg}^{2+} ;$ Pirita $=1 / 2 \mathrm{SO}_{4}^{2-} ;$ Cuarzo $=96 * \mathrm{H}_{4} \mathrm{SiO}_{4}$. Los resultados muestran la disolución equivalente a la presencia de halita, disolución de plagioclasa y precipitación de

Tabla 6. Procesos geoquímicos que explican la composición química del agua subterránea del área de Loreto, aplicando un modelo de balance de masas. Concentraciones en milimoles/l.

\begin{tabular}{|c|c|c|c|c|c|c|c|c|}
\hline $\begin{array}{l}\text { Muestra/Procesos } \\
\text { geoquímicos }\end{array}$ & 1 & 2 & 3 & 4 & 5 & 6 & 7 & 8 \\
\hline Grupo de agua & 1 & 1 & 2 & 2 & 3 & 3 & 3 & 3 \\
\hline Halita $\left(\mathrm{Cl}^{-}\right)$ & 2.031 & 2.829 & 1.26 & 1.19 & 0.54 & 0.741 & 0.74 & 2.99 \\
\hline Albita - Caolinita $\left(\mathrm{Na}^{+}\right)$ & 9.959 & 9.68 & 0.99 & 0.58 & 1.01 & 1.249 & 0.94 & 1.3 \\
\hline Anortita $\left(\mathrm{Ca}^{2+}\right)$ & 1.041 & 0.748 & 1.08 & 0.843 & 0.59 & 0.661 & 0.7 & 0.63 \\
\hline Biotita-Caolinita $(\mathrm{Mg})$ & 0.3 & 0.43 & 0.9 & 0.97 & 0 & 0 & 0 & 0 \\
\hline Olivino $\left(\mathrm{Mg}^{2+}\right)$ & 0 & 0 & 0 & 0 & 0.89 & 0.94 & 0.99 & 0.88 \\
\hline Pirita - Hematina $\left(\mathrm{SO}_{4}{ }^{2-}\right)$ & 0.21 & 0.23 & 0.1 & 0.09 & 0.08 & 0.1 & 0.08 & 0.173 \\
\hline Microclino - Caolinita (K) & 0.1 & 0 & 0 & 0.147 & 0.06 & 0.07 & 0.05 & 0.09 \\
\hline Int. iónico $\mathrm{K}-\mathrm{Ca}\left(\mathrm{Ca}^{2+}\right)$ & 0 & 0.062 & 0.14 & 0.147 & 0 & 0 & 0 & 0 \\
\hline Cuarzo $\left(\mathrm{H}_{4} \mathrm{SiO}_{4}\right)$ & -18.859 & -18.548 & -1.48 & 1.1 & -1.93 & -2.479 & -1.87 & -2.561 \\
\hline $\mathrm{CO}_{2}$ & 10.44 & 8.081 & 5.82 & 0.11 & 3.673 & 2.11 & 4 & 3.673 \\
\hline
\end{tabular}

cuarzo como procesos principales. Se aprecia que en el intemperismo originado mediante proceso de interacción agua-roca, se produce una apreciable disolución equivalente a la presencia de halita y transformación de plagioclasa en caolinita en todos los casos. La plagioclasa tipo albita es la fase mineralógica más abundante en la parte alta de la Sierra La Giganta y se considera su disolución como equivale en los manantiales muestreados para este trabajo; puede constituir del $50 \%$ al $90 \%$ de los fenocristales presentes en las lavas y cristales de la matriz rocosa (Bigioggero et al., 1996). Varios manantiales (muestras 5, 6, 7 y 8), ubicados principalmente en la región más occidental, originan también notables procesos de disolución de olivino presente en el basalto que compone el llamado Cinturón Andesítico Miocenico (CAM) ubicado en el área de estudio (Bigioggero et al., 1996). En todas las muestras se aprecia precipitación abundante de cuarzo, compuesto presente en las rocas de la Formación Comundú (Demant, 1975).

\section{Conclusiones}

En el área de Loreto, Baja California Sur (México), pueden distinguirse siete grupos de agua subterránea, correspondientes a manantiales de flujo local, pozos, manantiales termales y manantiales submarinos. A partir de su composición se identifican igual número de patrones hidrogeoquímicos, expresados mediante relaciones estequiométricas por medio de la notación $\mathrm{Na}^{+}+\mathrm{K}^{+}: \mathrm{Ca}^{2+}$ $: \mathrm{Mg}^{2+}-\mathrm{Cl}^{-}: \mathrm{HCO}_{3}^{-}: \mathrm{SO}_{4}{ }^{2-}$.

El origen de la composición química del agua en el área de estudio está controlado, principalmente, por procesos de interacción agua-roca los cuales incluyen disolución de halita, transformación de plagioclasa en caolinita, oxidación de pirita, intemperismo de biotita así como precipitación de cuarzo.

El origen de la composición química que adquiere el

Tabla 7. Procesos geoquímicos que explican la composición química del agua subterránea del área de Loreto, aplicando un modelo de balance de masas. Concentraciones en milimoles/l.

\begin{tabular}{|c|c|c|c|c|c|c|c|c|c|c|c|c|}
\hline $\begin{array}{l}\text { Muestra/Procesos } \\
\text { geoquímicos }\end{array}$ & 09-ene & 10-ene & 11-ene & 12-ene & 13-ene & 14-ene & 15-ene & 16-ene & 17-ene & 18-ene & $19-\mathrm{abr}$ & 20 \\
\hline Grupo de agua & 4 & 4 & 4 & 4 & 4 & 5 & 5 & 5 & 5 & 5 & 5 & 6 \\
\hline Halita $\left(\mathrm{Cl}^{-}\right)$ & 4.402 & 8.628 & 5.876 & 12.221 & 6.04 & 11.118 & 13.03 & 5.496 & 1.522 & 0.976 & 21.898 & 250.356 \\
\hline Albita $\left(\mathrm{Na}^{+}\right)$ & 0 & 0 & 0 & 0 & 0 & 0 & 0 & 0 & 0 & 0 & 0 & 0 \\
\hline Anortita & 0 & 0 & 0 & 0 & 0 & 0 & 0 & 0.346 & 0 & 0 & 2.398 & 0 \\
\hline Calcita $\left(\mathrm{Ca}^{2+}\right)$ & -2.52 & -2.844 & -2.989 & -1.41 & -3.253 & -4.942 & -5.247 & 0 & -5.075 & -5.17 & 0 & -68.513 \\
\hline Biotita-Caolinita $\left(\mathrm{Mg}^{2+}\right)$ & 0.119 & 0.906 & 0.611 & 0.617 & 1.074 & 1.715 & 2.346 & 1.026 & 0 & 0 & 1.724 & 16.389 \\
\hline Calcita - Dolomita $\left(\mathrm{Mg}^{2+}\right)$ & 0 & 0 & 0 & 0 & 0 & 0 & 0 & 0 & -0.141 & -0.199 & 0 & 0 \\
\hline Pirita - Hematita (SO4) & 0.284 & 1.546 & 0.976 & 1.121 & 0.669 & 0.97 & 1.011 & 0.296 & 0.064 & 0.051 & 0.57 & 4.07 \\
\hline Microclino - Caolinita (K) & 0 & 0 & 0 & 0 & 0 & 0 & 0 & 0 & 0 & 0 & 0 & 0.726 \\
\hline Int. iónico $\mathrm{Na}-\mathrm{Ca}\left(\mathrm{Ca}^{2+}\right)$ & 2.245 & 2.38 & 2.77 & 0.82 & 3.33 & 5.846 & 6.945 & 0.776 & 4.434 & 4.472 & 2.95 & 92.239 \\
\hline Int. Iónico $\mathrm{K}-\mathrm{Ca}\left(\mathrm{Ca}^{2+}\right)$ & 0.02 & 0.098 & 0.007 & 0.011 & 0.118 & 0.225 & 0.377 & 0.156 & 0 & 0.002 & 0.28 & 0 \\
\hline Cuarzo $\left(\mathrm{H}_{4} \mathrm{SiO}_{4}\right)$ & 0.121 & -0.404 & -0.307 & -0.311 & -0.616 & -0.843 & -1.264 & -0.384 & 0.3 & -4.826 & -0.849 & -1.478 \\
\hline $\mathrm{CO}_{2}$ & -5.966 & -2.474 & -2.535 & -2.5 & -0.467 & -1.39 & -0.246 & -0.732 & -4.972 & 0.3 & 7.076 & -101.682 \\
\hline
\end{tabular}

Muestras: 9- San Javier; 10- CNA3; 11- CNA8; 12- CNA4 (Nantra Bay); 13- San Nicolás; 14- CNA6; 15- CNA15; 16- Santo Domingo; 17- Naocojoa Chico; 18- Naocojoa Grande; 19- Juncalito; 20- Santispac; 1- Las Parras; 4- Santa Rosa. 
Flujos de Agua en Sedimentos y Rocas Volcanogénicas, Loreto

Tabla 8. Procesos geoquímicos que explican la composición química del agua subterránea salina del área de Loreto, aplicando un modelo de mezcla de aguas. Concentraciones en milimoles/1.

\begin{tabular}{|c|c|c|c|c|c|c|c|c|c|c|c|c|}
\hline Muestra & 09 -ene & 10 -ene & 11 -ene & 12-ene & 13-ene & 14-ene & 15 -ene & 16 -ene & 17-ene & 18-ene & 19-abr & 20 \\
\hline Grupo de agua & 4 & 4 & 4 & 4 & 4 & 5 & 5 & 5 & 5 & 5 & 5 & 6 \\
\hline \multicolumn{13}{|l|}{ Procesos geoquímicos } \\
\hline R1 & $99.10 \%$ & $98.60 \%$ & $99.20 \%$ & $97.50 \%$ & $98.80 \%$ & $97.70 \%$ & $97.30 \%$ & $99.30 \%$ & $99.70 \%$ & $99.80 \%$ & $97.80 \%$ & $64.20 \%$ \\
\hline R2 & $0.10 \%$ & $1.40 \%$ & $0.08 \%$ & $2.50 \%$ & $1.20 \%$ & $2.30 \%$ & $2.70 \%$ & $0.70 \%$ & $0.30 \%$ & $0.20 \%$ & $2.20 \%$ & $35.80 \%$ \\
\hline Halita $\left(\mathrm{Cl}^{-}\right)$ & 0.015 & 1.482 & 2.111 & -0.324 & -0.086 & -0.157 & -0.214 & -0.033 & -0.003 & -0.004 & -11.937 & 71.068 \\
\hline Albita $\left(\mathrm{Na}^{+}\right)$ & 0 & 0 & 0 & 0.72 & 0 & 0 & 0 & 0 & 0 & 0 & 0 & 0 \\
\hline Anortita & 0 & 0 & 0 & 0 & 0 & 0 & 0 & 0 & 0 & 0 & 0 & 0 \\
\hline Calcita $\left(\mathrm{Ca}^{2+}\right)$ & -5.219 & -2.429 & -2.872 & -1.54 & 0 & -6.221 & -4.467 & -5.547 & -5.176 & -5.22 & 4.11 & 79.567 \\
\hline Biotita-Caolinita $\left(\mathrm{Mg}^{2+}\right)$ & 0 & 0.305 & 0.296 & 0 & 0.558 & 0.769 & 1.236 & 0.429 & 0 & 0 & 0 & 2.091 \\
\hline Calcita - Dolomita $\left(\mathrm{Mg}^{2+}\right)$ & -0.247 & 0 & 0 & -0.436 & 0 & 0 & 0 & 0 & -0.268 & -0.281 & -4.11 & 0 \\
\hline Pirita - Hematita(SO4) & 0.095 & 0.669 & 0.812 & 0.592 & 0.412 & 0.495 & 0.453 & 0 & 0 & 0.009 & 0 & 0 \\
\hline Sulfato reducción & 0 & 0 & 0 & 0 & 0 & 0 & 0 & -0.047 & -0.005 & 0 & 0 & -3.554 \\
\hline Microclino-Caolinita (K) & 0 & 0 & 0 & 0 & 0 & 0 & 0 & 0 & 0 & 0 & 0 & 1.018 \\
\hline Int.iónico $\mathrm{Na}-\mathrm{Ca}\left(\mathrm{Ca}^{2+}\right)$ & 1.808 & 1.714 & 2.424 & 0 & 2.72 & 4.761 & 5.698 & 5.381 & 4.343 & 4.391 & 3.412 & 79.567 \\
\hline Int. Iónico $\mathrm{K}-\mathrm{Ca}\left(\mathrm{Ca}^{2+}\right)$ & 0.055 & 0.085 & 0.102 & -0.134 & 0.11 & 0.209 & 0.357 & 0.107 & 0.019 & 0.012 & 0.14 & 0 \\
\hline Cuarzo $\left(\mathrm{H}_{4} \mathrm{SiO}_{4}\right)$ & 0.146 & -0.09 & -0.144 & -1.493 & -0.347 & -0.351 & -0.686 & 0 & 0 & 0.288 & -0.137 & 5.285 \\
\hline $\mathrm{CO}_{2}$ & -5.899 & -2.851 & -2.64 & -2.293 & -0.77 & -1.969 & -0.941 & -4.002 & -4.836 & -4.79 & -1.566 & 46.591 \\
\hline
\end{tabular}

Muestras: 9- San Javier; 10- CNA3; 11- CNA8; 12- CNA4 (Nantra Bay); 13- San Nicolás; 14- CNA6; 15- CNA15; 16- Santo Domingo; 17- Naocojoa Chico; 18- Naocojoa Grande; 19- Juncalito; 20- Santispac; 1- Las Parras; 4- Santa Rosa; R1- Las Parras; R2: BC4.

agua de los grupos 4 y 5 fue posible confirmarlo y explicarlo mediante procesos de balance de masa y mezcla de aguas. Los principales procesos geoquímicos que controlan dicha composición son: la precipitación de calcita y dolomita (que se justifica por el ascenso de temperatura al mezclarse el agua fría con la caliente), el intercambio iónico entre el $\mathrm{Na}^{+}$ y $\mathrm{Ca}^{2+}$ así como entre $\mathrm{K}^{+}$y $\mathrm{Ca}^{2+}$ (al establecerse el nuevo balance por precipitación de calcita), oxidación de pirita o reducción de sulfato y disolución o precipitación de cuarzo.

El porcentaje de agua marina en la mezcla varía, en los manantiales de flujo local entre 0.1 y $2.7 \%$, y en el manantial termal alcanza $64 \%$. Los resultados confirman que la salinidad del agua obtenida en los pozos no está relacionada con la entrada de agua de mar, sino con la inducción de flujos regionales.

El entender el funcionamiento de agua subterránea en el área de estudio tiene varias implicaciones desde la perspectiva del ordenamiento ecológico territorial. Al determinar que sólo se tienen zonas de descarga de flujos locales en el área de estudio es indicativo de que una parte importante del agua de lluvia infiltrada continúa su recorrido subterráneo hacia fuera del territorio de la Península de Baja California como flujo intermedio y regional, es decir, hacia el Golfo de California. Los manantiales submarinos detectados sugieren que esta posibilidad es plausible. El agua subterránea extraída por los pozos es una mezcla de flujos intermedio y regional, siendo posible que la mezcla extraída incremente la componente termal a medida que la extracción aumenta en el tiempo.

Los diferentes tipos de flujos están siendo utilizados por la agricultura; sin embargo, si esta extracción no se modera y al contrario, aumenta como respuesta al incremento poblacional esto implicará que la calidad química del agua obtenida por pozos continuará en su deterioro al ir evolucionando hacia la calidad de los flujos regionales (de mayor salinidad y temperatura). Es decir, hay una disponibilidad baja de agua adecuada para fines de uso agrícola y para asentamientos humanos. Esto da la pauta de la necesidad de entender el funcionamiento de los sistemas de flujo para incluirlos en el manejo del agua subterránea que pueda ser propuesto en los planes de ordenamiento ecológico territorial en regiones áridas como la aquí estudiada.

\section{Agradecimientos}

A CONACYT por la beca otorgada a Antalia González Abraham (número de registro 189567). El financiamiento provino de los proyectos AECI-CONACyT-SEP y SEMARNAT-2002-01-C01-00318 dados a Ricardo Rodríguez Estrella. Agradecemos a Bruno Granados por su apoyo en el trabajo de campo, así como a los revisores (anónimo y Eduardo H. Graniel Castro) del manuscrito original cuyas recomendaciones enriquecieron el contenido del presente trabajo.

\section{Referencias}

Appelo, C.A.J., Postma, D., 1993, Geochemistry, groundwater and pollution: Leiden, The Netherlands, A. A. Balkema Publishers, 536 p.

American Public Health Association-American Water Works AssociationWater Environment Federation (APHA-AWWA-WPCF), 1989, Standard methods for the examination of water and waste water, $17^{\text {th }}$ Edition: Washington, D.C., USA, American Public Health Association, $1268 \mathrm{p}$.

Armienta, M.A., Rodríguez, R., Aguayo, A., Ceniceros, N., Villaseñor, G., Cruz, O., 1997, Arsenic contamination of groundwater at Zimapán, México: Hydrogeology Journal, 5, 39-46.

Beal, C.H., 1948, Reconnaissance geology and soil possibilities of Baja California Mexico: Geological Society of America Memoir, 31, 138. 
Bigioggero, B., Corona-Chávez, P.C., Tunesi, A., 1996, Características estratigráficas, petrológicas y extinción del cinturón andesítico miocénico de la región de Loreto-Las Parras, Baja California Sur, México: Revista Mexicana de Ciencias Geológicas, 13, 152-173.

Canet, C., Prol-Ledesma, R.M., Torres-Alvarado, I., Gilg, H.A., Villanueva, R.E., Lozano-Santa Cruz, R., 2005, Silica-carbonates stromatolites related to coastal hydrothermal venting in Bahía Concepción, Baja California Sur, México: Sedimentary Geology, 174, 97-113.

Cardona, A., 2003, Evaluación de la Contaminación difusa del agua subterránea (resumen), en IV Congreso Nacional de Aguas Subterráneas: San Luís Potosí. S.L.P, México, 26.

Cardona, A., Carrillo-Rivera, J.J., Huizar-Álvarez, R., Granel-Castro, E., 2004, Salinization in coastal aquifers of arid zones: an example from Santo Domingo, Baja California Sur, Mexico: Environmental Geology, 45, 350-366.

Carrillo-Rivera, J.J., 2000, Application of the groundwater-balance equation to indicate interbasin and vertical flow in two semi-arid drainage basins, Mexico: Hydrogeology Journal, 8, 503-520.

Carrillo-Rivera, J.J., Cardona, A., Moss, D., 1996, Importance of the vertical component of groundwater flow: a hydrogeochemical approach in the valley of San Luis Potosi, Mexico: Journal of Hydrology, 185, 23-44.

Carrillo-Rivera, J.J. y Cardona, A., 2008, Groundwater flow system response in thick aquifer units: theory and practice in Mexico (Trabajos selectos), en XXXIII-IAH Congreso Internacional, Asociación Internacional de Hidrogeólogos: Zacatecas, Zacatecas, México Editorial Balkema, Taylor y Francis Group, 25-46.

Comisión Nacional del Agua (CNA), 1991, Sinopsis geohidrológica del estado de Baja California Sur: Subdirección General de Administración del Agua, Secretaría de Agricultura, Ganadería, Desarrollo Rural, Pesca y Alimentación, 81 p.

Comisión Nacional del Agua (CONAGUA), 2006, Actualización Geohidrológica de los acuíferos de San Juan B. Londó y Loreto, B. C. S, Informe Final: Lesser y Asociados S. A de C. V.

Comisión Nacional de Areas Naturales Protegidas (CONANP), 2000, Programa de Manejo del Parque Nacional Bahía de Loreto: SEMARNAT, D.F., 182 p.

Comisión Federal de Electricidad (CFE), 1998. Síntesis Geológica de las Tres Vírgenes, BCS, México, en Marsily. G., 1986., Quantitative hydrogeology: groundwater hydrology for engineers: Academic Press, New York, 440 p.

Demant, A., 1975, Caracteres químicos principales del vulcanismo terciario y cuaternario de Baja California Sur, Relaciones con la evolución del margen continental Pacifico de México: Revista del Instituto de Geología, UNAM, 75, 19-65.

Dorsey, R. J., Stone, K. A., Umhoefer, P. J., 1997, Stratigraphy, sedimentology, and tectonic development of the southeastern Pliocene Loreto Basin, Baja California Sur, México, en Johnson, M. E., Ledesma-Vázquez, J. (eds.), Pliocene carbonates and related facies flanking the Gulf of California, Baja California, Mexico: Boulder, Colorado, The Geological Society of America, Special Paper 318, 83-110.

Drever, J. I. 1982. Geochemistry of natural waters: New Jersey, PrenticeHall, Inc., 388.

Edmunds, W. M., Darling, W. G., Kinniburgh, D. G., 1988, Solute profile techniques for recharge estimation in semi-arid and arid terrain, en Simmers, I. (ed.), Estimation of natural groundwater recharge: Dordecht, D. Reidel Publishing Company, 139-157.

Fagundo J. R., 1996, Química del agua kárstica, Editorial Grupo de Investigación Recursos Hídricos y Geología Ambiental, Universidad de Granada, España: 11-119.

Fagundo. J. R., 1998, Patrones hidrogeoquímicos y relaciones matemáticas en aguas naturales: Ingeniería Hidráulica, 19, 62-78.

Fagundo, J. R., González, P., Suárez, M., Fagundo-Sierra, J., Melián, C., Llerena, M., Sánchez, L, 2000, Orígen de la composición química de las aguas naturales y minerales procedentes de acuíferos no carbonatados de la Sierra del Rosario, Contribución a la Educación y la Protección Ambiental: La Habana, Editorial Academia, 1,
204-210.

Fagundo, J. R., González, P., Suárez, M. Fagundo-Sierra, J., Melián, C, Gimenéz. S., González, A., Romero, E. Orihuela, D. 2004. Procesos geoquímicos en un acuífero costero en contacto con un humedal. En: humedales de Iberoamérica. Red Iberoamericana de humedales. Programa CYTED, J. J. Neiff (editor). 188-203.

Fagundo, J.R., P. González, M. Suárez Muñoz, J. Fagundo-Sierra, C. Melián, E. Álvarez, HIDROGEOQUIM, 2005, Contribución a la Educación y Protección Ambiental: ISCTN, 6, Q 58-67, La Habana.

Fagundo, J. R., González, P., Fagundo Sierra, J., Álvarez, E., Suárez, M., Melián, C., 2006. Application of hidrogeochemical modeling to characterization and water quality control of coastal karst aquifer, en Demuth, S., Gustard, A., Planos, E., Scatena, F., Servat, E. (eds.), 2006, Climate variability and change: hydrological impacts: The Netherlands, IAHS Publication 308, 596-600.

Fagundo, J. R., Carrillo-Rivera, J. J., Antigüedad, I., González, P., Peláez, R., Hernández, R., Cáceres, D., Hernández-Santana, J. R., Suárez, M., Melián, C., Rodríguez-Piña, M., 2008, Chemical and geological control of spring water in Eastern Guaniguanico, Pinar del Río, Cuba: Environmental Geology, Springer-Verlag, 247-267.

Fagundo-Sierra, J., J.R. Fagundo, P. González, M. Suárez, 2001, Modelación de las aguas naturales Contribución a la Educación y la Protección Ambiental: La Habana, Cuba ISCTN. 2, 8 .

García E., 1988, Modificaciones al sistema de clasificación de Köppen (para adaptarlo a las condiciones de la Republica Mexicana): Instituto de Geografía, Universidad Nacional Autónoma de México, Distrito Federal, México, 246 p.

Garrels, R. M., Mackenzie, F.T., 1967, Origin of the chemicals composition of springs and lakes, equilibrium concepts in natural water systems: American Chemical Society, Advances in Chemistry Series, 67, 222-242

Heim, A., 1922, Notes of the tertiary of southern lower California: Geological Magazine, 59, 529-547.

Instituto de Geofísica, 1986, Estudio Geohidrológico-Geofísico en la cuenca de San Juan Bautista Londó, Municipio Comondú, Reporte para SARH, México: Instituto de Geofísica, Universidad Nacional Autónoma de México, Coyoacán, México. 1-122.

Instituto Nacional de Estadística y Geografía (INEGI), 2005, II Conteo de Población y Vivienda, consultado en línea http://www.inegi.org.mx/ sistemas/TabuladosBasicos/Default.aspx?c=10398\&s=est.

Mina-Uhink, F, 1957, Bosquejo geológico del territorio sur de la Baja California, México: Boletín de la Asociación Mexicana de Geólogos Petroleros, 9, 139-270.

Molina-Maldonado, A., 1997, Diferenciación hidrogeoquímica de los sistemas de flujo de agua subterránea en la zona sur-centro del estado de Aguascalientes, México: B Sc Thesis (Geology), Facultad de Ingeniería, UNAM.

Parkhurst, D. L., Plummer, L. N., Thordtenson, D. C., 1982, BALANCE - A computer program for calculating mass transfer for geochemical reactions in ground water: U.S. Geological Survey Water-Resources Investigations Report 82-14.

Prol-Ledesma, R.M., Canet, A., Torres-Vera, M.A., Forrest, M.J., Armienta, M.A., 2007, Vent fluid chemistry in Bahía Concepción coastal submarine hydrothermal system, Baja California Sur, Mexico: Journal of Vulcanology and Geothermal Research, 137, 311-328.

Schoeller, H. 1960. Salinity of groundwater, evapotranspiration and recharge of aquifers en: Appelo, C.A.J., Postma, D., 1993, Geochemistry, groundwater and pollution: Netherlands, A. A. Balkema Publishers, 536 p.

Steinitz, C. Faris, R., Vargas-Moreno, J. C., Huang, G., Shiau-Yun, L., Arizpe, O., Angeles, M., Ivanova, A., Gámez, A. E., Baird, K., Maddhock, T., Ajami, H., Huato, L., Haro. M.J., Flaxman, M., Ganster, P., Villegas, A., López, C., 2005, Futuros alternativos para la región de Loreto, Baja California Sur, México: Informe Técnico. Harvard University.

Stiff, H. A., 1951, The interpretation of chemical water analysis by means of patterns: Journal of Petroleum Technology, 1951, 15-17. 
Tóth, J., 2000, Las aguas subterráneas como agente geológico: causas, procesos y manifestaciones: Boletín Geológico y Minero, 111, 9-25.

Zamora, V. M., 2008, Geoquímica de las aguas subterráneas de la Provincia de Las Tuna: La Habana, Universidad de La Habana, Cuba, Facultad de Química, tesis doctoral 180 p.

Manuscrito recibido: Junio 15, 2010.

Manuscrito corregido recibido: Septiembre 27, 2010.

Manuscrito aceptado: Diciembre 20, 2010. 